\title{
Implante experimental de substituto arterial de polidimetilsiloxano com reforço de tecido
}

\author{
de poliéster em coelhos
}

Tese apresentada à Faculdade de Medicina da Universidade de São Paulo para obtenção de título de Doutor em Ciências

Programa de Clínica Cirúrgica

Orientador: Prof. Dr. Nelson De Luccia

São Paulo

2013 
Dados Internacionais de Catalogação na Publicação (CIP)

Preparada pela Biblioteca da

Faculdade de Medicina da Universidade de São Paulo

Creprodução autorizada pelo autor

\section{Ribas, Laila Massad}

Implante experimental de substituto arterial de polidimetilsiloxano com reforço de tecido de poliéster em coelhos / Laila Massad Ribas. -- São Paulo, 2013.

Tese(doutorado)--Faculdade de Medicina da Universidade de São Paulo.

Programa de Clínica Cirúrgica.

Orientador: Nelson De Luccia.

Descritores: 1.Prótese vascular 2.Polidimetilsiloxanos 3.Silicones 4.Poliésteres 5.Aorta abdominal/cirurgia 6.Coelhos

USP/FM/DBD-143/13 
Dedico esta tese ao meu marido Carlos Eduardo Ribas e a minha filha Isabela Massad Ribas, os amores da minha vida! 


\section{Agradecimentos}

Ao Prof. Dr. Nelson de Luccia que fez muito mais do que apenas orientar meu trabalho. Dedicou seu tempo ao longo desses anos para que eu me tornasse uma profissional muito melhor. Aproveitou cada minuto para transformar uma simples reunião em uma aula de cirurgia vascular.

Ao Prof. Dr. Eduardo Massad pelas análises estatísticas e que como sempre me coorientou com todo seu amor e carinho.

Ao Paulo Sasssaki, que me ajudou em todos os aspectos enquanto poderia estar se dedicando a sua própria tese.

A Inez Onashi pelo carinho, apoio, amizade, por me ajudar nos procedimentos cirúrgicos e pela presença tão fundamental semana a semana.

A Fernanda Appolônio pelas ideias brilhantes que deram início a todo projeto.

A Karina Paula Domingos Rosa Schneidwind e a Fabio Rodrigues Ferreira do Espirito Santo pela ajuda nos procedimentos cirúrgicos.

A minha querida professora de inglês Adriana Toujeiro sem a qual eu não teria iniciado nem mesmo meu mestrado.

Aos funcionários da técnica cirúrgica Claudio Antônio Vidotti, Elias Aparecido Marcelino e Ourisval Santana Santos pela imensa ajuda, por me tratarem com tanto carinho e pelo respeito aos animais. 


\section{Normalização adotada}

Esta tese está de acordo com as seguintes normas, em vigor no momento desta publicação:

Referências: adaptado de International Committee of Medical Journals Editors (Vancouver).

Universidade de São Paulo. Faculdade de Medicina. Divisão de Biblioteca e Documentação. Guia de apresentação de dissertações, teses e monografias. Elaborado por Anneliese Carneiro da Cunha, Maria Julia de A. L. Freddi, Maria F. Crestana, Marinalva de Souza Aragão, Suely Campos Cardoso, Valéria Vilhena. 3a ed. São Paulo: Divisão de Biblioteca e Documentação; 2011.

Abreviaturas dos títulos dos periódicos de acordo com List of Journals Indexed in Index Medicus. 


\section{Sumário}

Resumo

Summary

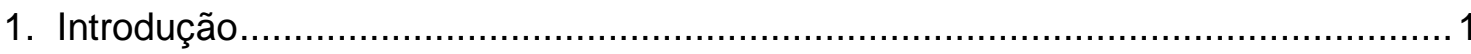

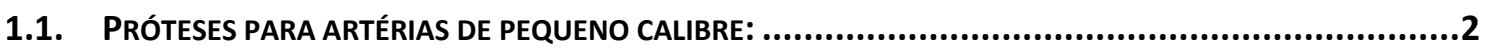

1.2. ENDOTELZAÇÃO DE ENXERTOS:..................................................................................

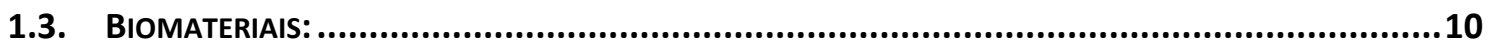

1.4. MODELOS ANIMAIS PARA CIRURGIA VASCULAR: ..........................................................15

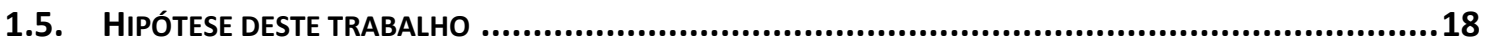

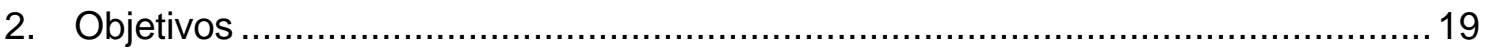

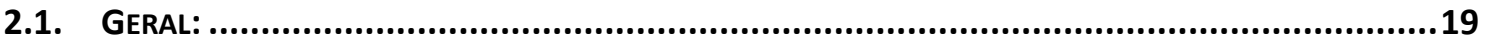

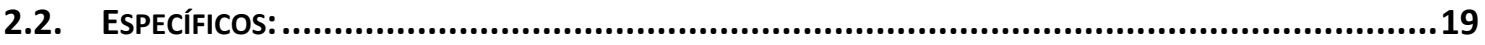

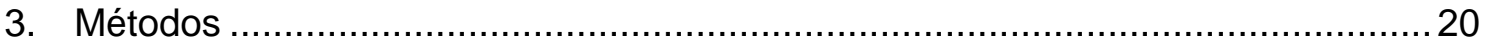

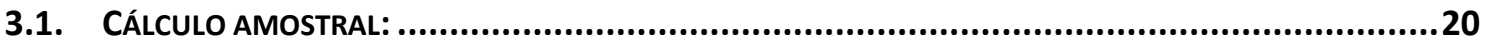

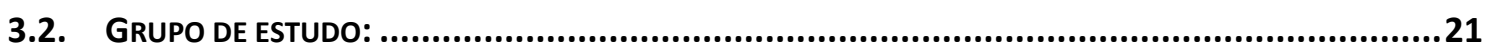

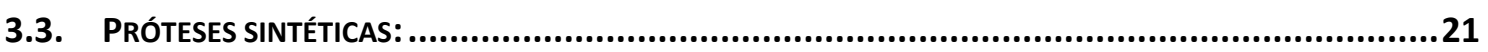

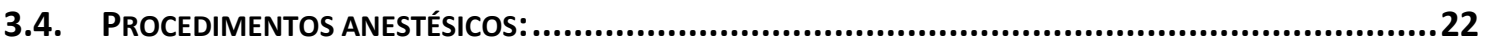

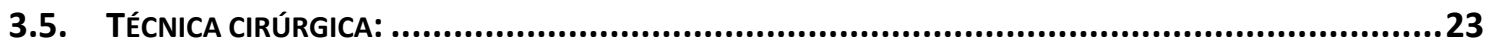

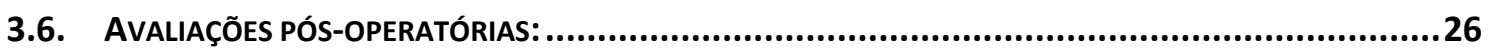

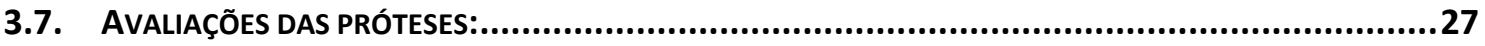

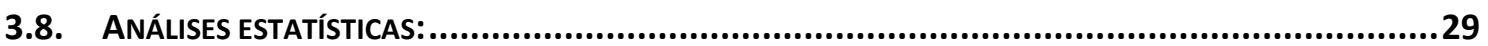

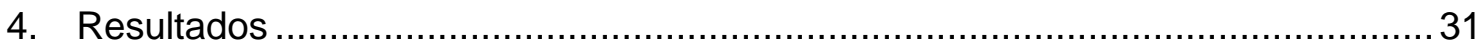

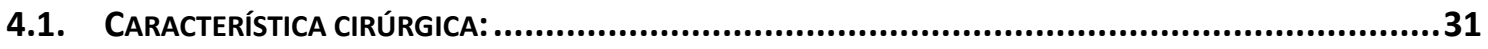

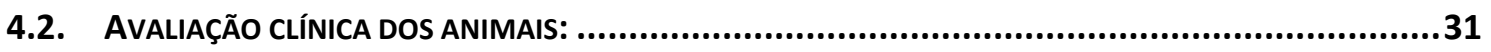

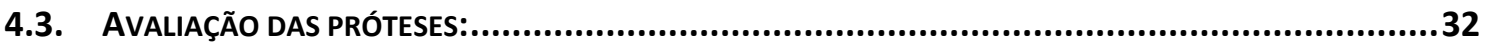

4.4. ANÁLISE DO GRAU DE ESTENOSE DAS PRÓtESES PATENTES ............................................36

4.5. AVALIAÇÃO DO TEMPO DE CLAMPEAMENTO DA AORTA .................................................38

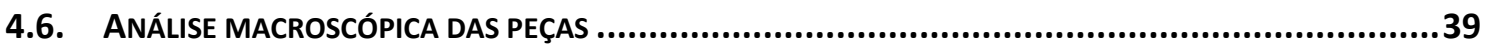

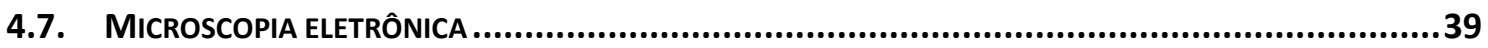

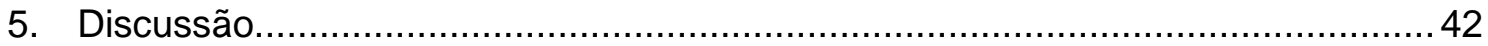




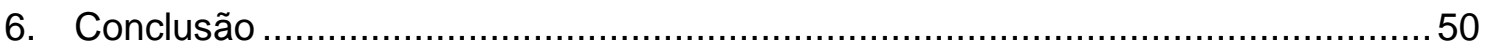

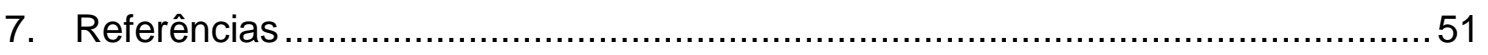




\section{Resumo}

Ribas LM. Implante experimental de substituto arterial de polidimetilsiloxano com reforço de tecido de poliéster em coelhos [tese]. São Paulo: Faculdade de Medicina, Universidade de São Paulo; 2013.

O presente estudo avaliou próteses vasculares de pequeno calibre feitas de polidimetilsiloxano (PDMS) com reforço de poliéster implantadas em aorta de coelhos através de fluoroscopia. Os objetivos do estudo foram: (1) analisar tubo de PDMS com reforço de poliéster implantado em aorta de coelhos como possível material para prótese vascular, (2) avaliar a patência das próteses através de fluoroscopia, (3) avaliar a condição de implante cirúrgico; (4) avaliar o comportamento macroscópico biológico do implante e (5) analisar o modelo experimental proposto. Próteses vasculares de PDMS foram implantadas na aorta infrarrenal de 64 coelhos cedidos pelo biotério da Faculdade de Medicina da Univesidade de São Paulo. Os exames de fluoroscopia foram realizados em até 150 dias após implantação cirúrgica. As próteses de PDMS foram classificadas em ocluídas e patentes, sendo essas sub-classificadas em diferentes graus de estenose. O tempo de clampeamento da aorta foi aferido durante os procedimentos cirúrgicos. De maneira amostral peças foram encaminhadas para microscopia eletrônica para verificação de endotelização das próteses. As análises estatísticas foram feitas através de teste t-Studant, teste ANOVA e Kaplan-Meier. Dos 64 animais que receberam a prótese, trinta $(46,88 \%)$ apresentaram boa evolução clínica, vinte e três $(35,94 \%)$ morreram e onze $(17,18 \%)$ apresentaram paraplegia de membros posteriores. A patência das próteses em 30 dias foi de $87 \%$ ( $\pm 6,7)$, em 60 dias foi de $73 \%( \pm 9,3)$, em 90 dias foi de $57 \%( \pm 11)$ e em 120 dias foi de $48 \%( \pm 12)$. Cinquenta por cento (oito) das próteses patente não apresentaram nenhum grau de estenose, $35,5 \%$ (seis) apresentaram cinquenta por cento ou menos de estenose e $12,5 \%$ (dois) apresentaram estenose entre cinquenta e setenta por cento. Nenhum animal apresentou estenose maior que $70 \%$. O tempo médio de clampeamento da aorta foi de 52 minutos. Não houve diferença significante nem na associação entre tempo de clampeamento da aorta e a evolução clínica dos animais $(p=0,67)$ nem na associação entre o tempo de clampeamento e a patência das próteses $(t=1,35 ; p=0,18)$. As peças encaminhadas para microscopia apresentaram crescimento endotelial a partir do vaso nativo em direção à prótese de PDMS. Foi possível concluir com este estudo que o PDMS demonstrou-se um material adequado para futuras pesquisas no ramo de próteses vasculares e que o uso da fluoroscopia na avaliação dessas próteses foi de fundamental importância na determinação da patência dos implantes.

Descritores: 1.Próteses vasculares 2. Polidimetilsiloxanos 3. Silicones 4. Poliésteres 5.Aorta abdominal/cirurgia 6.Coelhos 


\section{Summary}

Ribas LM. Experimental implant of arterial substitute of polydimethylsiloxane reinforced with polyester fabric in rabbits [thesis]. "São Paulo: Faculdade de Medicina, Universidade de São Paulo"; 2013.

The present study evaluated small caliber vascular prostheses made of polydimethylsiloxane (PDMS) with polyester reinforcement implanted in the aorta of rabbits by fluoroscopy. The study objectives were: (1) analyze PDMS tube with polyester reinforcement implanted in the aorta of rabbits as possible material for vascular prosthesis, (2) assess the patency of the prosthesis through fluoroscopy, (3) assess the condition of surgical implant (4) evaluate the macroscopic behavior of biological implant and (5) analyze the proposed experimental model. Vascular prostheses were implanted in PDMS infrarenal aorta of 64 rabbits assigned by the animal house of the Faculty of Medicine of the University of São Paulo. Fluoroscopic examinations were performed within 150 days after surgical implantation. The prosthesis of PDMS were classified into occluded and patents, these being sub-classified into different degrees of stenosis. The time of aortic clamping was measured during surgical procedures. Sample pieces were sent for electron microscopy to check endothelialization of prostheses. Statistical analyzes were performed using t-test Studant, ANOVA and Kaplan-Meier. Of the 64 animals that received the prosthesis, thirty $(46.88 \%)$ showed clinical improvement, twenty-three $(35.94 \%)$ died and eleven $(17.18 \%)$ had paraplegia of hind limbs. The patency of the prosthesis in 30 days was $87 \%( \pm 6.7)$, at 60 days was $73 \%( \pm 9.3)$, at 90 days was $57 \%( \pm 11)$ and at 120 days was $48 \%( \pm 12)$. Fifty percent (eight) of the prosthesis patent did not present any degree of stenosis, 35.5\% (six) had fifty percent or less of stenosis and $12.5 \%$ (two) had stenosis between fifty and seventy percent. No animal showed stenosis greater than $70 \%$. The mean aortic clamping was 52 minutes. There was no significant difference in the association between duration of aortic clamping and clinical evolution of animals $(p=0.67)$ nor the association between clamping time and patency of the prosthesis $(t=1.35, p=0.18)$. The parts sent for microscopy showed endothelial growth from the native vessel toward the prosthesis PDMS. It can be concluded from this study that the PDMS proved to be a suitable material for future research in the field of vascular prostheses and the use of fluoroscopy in the evaluation of these prostheses was of fundamental importance in determining the patency of the implants.

Descriptors: 1.Vascular prosthesis 2.Polydimethilsiloxane 3.Silicones 4.Polyesters 5.Abdominal aorta/surgery 6.Rabbits 


\section{Introdução}

Próteses vasculares têm o objetivo de conduzir o fluxo sanguíneo e são utilizadas em substituição a essa função em vasos acometidos por obstrução, dilatação ou destruição no caso de trauma'.

Quando se trata dessa substituição em vasos de grande calibre, como a aorta, as ilíacas e as femorais, essa função é suprida razoavelmente pelos tubos sintéticos disponíveis no momento, como o politetrafluoretileno (PTFE) e o Dacron ${ }^{2-5}$. Contudo, em vasos de pequeno calibre nenhum desses materiais se mostrou superior à veia safena ${ }^{6-10}$, enxerto esse que tem funcionamento comprovado e que acabou por se tornar o conduto mais comumente utilizado em humanos para cirurgia de revascularização periférica ${ }^{11-14}$.

O grande desafio parece ocorrer nas situações em que não há veia disponível para substituição arterial. O número de pesquisas nesse campo é grande e diversas são as opções já estudadas para a solução desse problema. Veias criopreservadas de doadores ${ }^{15,16}$ e materiais biossintéticos são alguns exemplos da diversidade que se encontra nos estudos de cirurgia vascular ${ }^{17,18}$, mas apesar disso, parece que a busca de um substituto arterial eficiente para vasos de pequeno calibre ainda continua aberta ${ }^{19,20}$. 


\subsection{Próteses para artérias de pequeno calibre:}

O primeiro relato de substituto vascular data de 1952, quando Voorhees descreveu seu primeiro trabalho com o uso de um tecido chamado Vinyon- $\mathrm{N}$ (policloreto de vinila ou PVC) utilizado como prótese de aorta de 15 cães $^{21}$.

Essa linha de pesquisa teve continuidade com o desenvolvimento de tecidos sintéticos relativamente impermeáveis, como o nylon (poliamida) em 1955, sendo as primeiras próteses confeccionadas artesanalmente ao se costurar o tecido sobre si mesmo criando estrutura tubular implantável através de suturas no indivíduo receptor ${ }^{22}$.

A ideia, na época revolucionária, foi eficiente e simples, porém o nylon foi logo no inicio da experiência substituído pelo poliéster (sob o nome comercial de Dacron) ${ }^{23}$ e esse material, em diferentes formas de trançado, foi o que desde então persistiu como a prótese mais utilizada, particularmente nas artérias de grande calibre como a aorta, ilíacas e femorais ${ }^{3}$.

Para essas próteses de poliéster fabricadas em máquinas têxteis duas grandes modalidades emergiram, que foram as chamadas próteses tecidas (em inglês "woven") ou tricotadas (em inglês "knitted"). Por um tempo este conceito foi muito valorizado, por aspectos de técnica operatória e de crença no princípio da habitação celular ${ }^{24}$.

As próteses tricotadas possuem maior espaço entre as fibras do tecido, e, portanto são mais maleáveis e permitem a passagem da agulha dos fios de sutura com maior facilidade. Portanto seu manuseio é melhor ${ }^{25}$. Entretanto, esse espaço maior entre as fibras, permite a passagem do sangue e isso fez 
com que fosse necessário um tempo conhecido como de pré coagulação, no qual após a liberação inicial das anastomoses esperava-se que houvesse formação de coágulos entre as tramas do tecido para que o enxerto se tornasse impermeável. Isto provocava maior sangramento intraoperatório, mas o benefício do melhor manuseio e de melhor integração futura da prótese pela habitação celular são os argumentos que justificam a escolha ${ }^{26}$. A necessidade de pré-coagulação das próteses tricotadas, por exemplo, foi resolvida com o uso de compostos proteicos incorporados à trama dos tecidos ${ }^{27}$.

As próteses tecidas ("woven") são mais rígidas, e portanto de mais difícil manuseio. Entretanto são impermeáveis e não necessitam tempo de pré coagulação nem revestimento interno com proteínas ${ }^{28,29}$.

Cerca de vinte anos após o início da experiência com as próteses feitas com tecidos sintéticos de poliéster, surge o politetrafluoetileno expandido (PTFEe).

Descoberto acidentalmente por Roy J. Plunkett (1910-1994) para a empresa DuPont, em 1938, e apresentado para fins comerciais em 1946, o PTFE é um polímero similar ao polietileno e que já havia sido utilizado como prótese vascular em 1959, porém na forma de tecido com as fibras trançadas ${ }^{30}$. Foi então desenvolvido como prótese para veias, em 1972 por Soyer e colaboradores $^{31}$, e para artérias, em 1973 por Matsumoto e colaboradores ${ }^{32}$. Desde então o PTFEe ganhou espaço como prótese vascular com a proposta de substituir artérias de menor calibre como as abaixo da articulação do joelho. Além disso, vem sendo amplamente utilizado em acessos dialíticos ${ }^{33}$ e até mesmo como substituto ureteral ${ }^{34}$. 
Mesmo sem atingirem totalmente seus objetivos quanto à substituição de função de artérias de pequeno calibre, o politetrafluoroetileno e o poliéster persistiram como os materiais mais empregados em todo o período desde 0 inicio do desenvolvimento das próteses vasculares até o presente.

O principal avanço tecnológico que ocorreu a partir da década de noventa foi o advento das próteses para uso sem sutura $^{35}$, e que são liberadas a partir de bainhas plásticas onde são comprimidas até que ocorra o processo de liberação. Para que não houvesse a necessidade de suturas o mecanismo desenvolvido foi o de estruturas metálicas, incorporadas à parte plástica ou tecida da prótese, que ao serem liberadas das bainhas de contenção permitissem a justaposição em regiões saudáveis da árvore vascular, permitindo o restabelecimento do fluxo sanguíneo em novo trajeto artificial ${ }^{36}$.

Essa revolução tecnológica provocou mudanças nos conceitos até então vigentes sobre as características desejáveis das próteses vasculares. Em vez de facilidade ao manuseio para a aposição de suturas, tornaram-se mais importantes a espessura dos componentes para diminuir o perfil e permitir a introdução em vasos de menor calibre, assim como a flexibilidade para que os sistemas de liberação pudessem navegar em vasos mais tortuosos ${ }^{37,38}$.

Apesar do advento das próteses para liberação endoluminar dirigir a pesquisa nesta área para este tipo de tecnologia, próteses para implante através de intervenções cirúrgicas abertas, particularmente para artérias de calibre inferior a quatro milímetros ainda representam área que não foi resolvida pela tecnologia atual e justificam este tipo de investimento ${ }^{39}$. 
Durante cerca de sessenta anos, a pesquisa relacionada a próteses vasculares estudou, além dos diferentes tipos de materiais, aspectos relevantes à habitação dos tecidos protéticos por células do paciente, e se possível, o revestimento da superfície luminar do tubo sintético por células endoteliais, processo esse chamado de endotelização ${ }^{40}$.

\subsection{Endotelização de enxertos:}

Segundo livro texto de Moncada e Higgs em 2010 ${ }^{41}$, o endotélio, situado como interface entre sangue e tecidos, atua como papel central nas funções críticas do sistema cardiovascular, como regulação do tônus vascular, troca de fluidos e solutos, homeostasia, coagulação, respostas inflamatórias e angiogênese. Essas ações são exercidas por substâncias liberadas pelo endotélio, como o óxido nítrico, considerado o mais importante fator endotelial ${ }^{42}$ ao lado da prostaciclina e do fator hiperpolarizante derivado do endotélio, pois promovem o balanço entre fluidez e trombose e mantêm o tônus vascular ${ }^{43-45}$.

O endotélio pode também gerar fatores contráteis conhecidos como as endotelinas, a angiotensina II, as prostaglandinas vasoconstritoras e espécies reativas de oxigênio ${ }^{46-48}$.

Se as células endoteliais promovem resistência à formação de trombos, então o endotélio pode ser considerado um fator essencial na manutenção de uma patência de enxertos em longo prazo ${ }^{18}$. Por conta disto, a habitação de 
endotélio no leito de enxertos sintéticos é tão procurada como a busca do substituto em si.

Admite-se que o endotélio possa revestir o interior de um enxerto ou prótese a partir do crescimento do vaso nativo na linha de sutura, ou de células circulantes na corrente sanguínea ${ }^{40,49}$. A penetração de tecido periférico adjacente ao corpo da prótese, fator para o qual a porosidade da mesma seria importante, é apontada nesse tópico em particular ${ }^{50}$. Essa teoria, apesar de frequentemente aceita, não é comprovada, e de fato, apenas o crescimento de endotélio por poucos milímetros além da linha de sutura é documentada ${ }^{51,52}$. Apesar desse fato não afetar o desempenho clínico nas implantações de próteses de grandes calibres, como na aorta ou ilíaca, isto pode contribuir significativamente para a alta taxa de falhas em implantes de pequeno e médio calibre $^{53,54}$.

A porosidade de uma prótese pode ser alterada durante sua fabricação de acordo com as configurações dos nós e das fibras do material ${ }^{17}$.

Por conta da possível endotelização dos enxertos através dos poros das próteses sintéticas, pesquisadores consideraram diversos níveis de porosidade, mas com resultados contraditórios.

Golden et al em $1990^{55}$ realizaram estudo de próteses de PTFEe em babuínos. Testaram tubos com porosidade entre 10 e $90 \mu \mathrm{m}$ (distância internodal) e concluíram que os tubos com baixa porosidade (entre 10 e $30 \mu \mathrm{m}$ ) e com alta porosidade (90 $\mu \mathrm{m})$ apresentaram falhas na endotelização luminal, enquanto que os tubos com porosidade media $(60 \mu \mathrm{m})$ apresentaram endotelização completa. 
Reidy, Chao e Kirkman em $1986^{56}$, Clowes, Kirkman e Reidy em $1986^{57}$ e Clowes, Zacharias e Kirkman em $1987^{50}$ também admitiram que a porosidade ideal é de $60 \mu \mathrm{m}$, porém Lumsden et al em $1996^{58}$ reduziram a hiperplasia intimal aplicando silicone em tubos de PTFEe de pequeno calibre. O silicone aplicado nestes tubos era impermeável, impossibilitando a passagem de células para o lúmen da prótese e mesmo assim apresentaram resultados melhores que aqueles sem o revestimento.

Além disso, Contreras, Quist e Logerfo em $2000^{59}$ demonstraram que o revestimento externo de poliuretano impermeável aplicado em enxertos de PTFEe de pequeno calibre não tiveram efeito sobre a formação intimal, independentemente da porosidade.

Além da porosidade, uma técnica de semeadura de células endoteliais vem sendo abordada há mais de 30 anos na tentativa de melhorar 0 revestimento endotelial ${ }^{60}$. As células do endotélio a serem cultivadas já foram coletadas de diferentes locais, como veia jugular externa ${ }^{61}$, veia safena ${ }^{62}$, veia umbilical $^{63}$ e tecido adiposo humano ${ }^{64}$. Até mesmo células endoteliais de babuínos já foram testadas como fonte de células endoteliais ${ }^{65}$. Graham et al em $1982^{66}$ e Koveker et al em $1988^{67}$ e Ombrellaro et al em $1996^{68}$ demonstraram que a semeadura de células endoteliais em próteses de PTFEe antes da implantação em cães aumentou a endotelização dos mesmos.

A principal razão para endotelização de próteses e enxertos é prevenir a hiperplasia intimal, grande causa de falha nesses substitutos ${ }^{69}$. Baseados em revisões de outras pesquisas Davies et al em $1995^{70}$ acreditavam que as veias apresentam maior taxa de sucesso como substituto arterial, pois não são 
materiais inertes e mantém uma parte considerável de endotélio e funções de células musculares lisas, o que não ocorre nos materiais sintéticos. Isso acaba por refletir no crescimento das células da túnica íntima, porém, embora estudos experimentais sobre semeadura dos enxertos com células progenitoras endoteliais tenha demonstrado excelentes resultados nos endotelização do enxerto, nenhum desses estudos relatam efeitos favoráveis sobre os pontos finais mais clinicamente relevantes, tais como hiperplasia intimal ou patência de enxerto $^{71,72}$.

Além disso, Conte et al em $1995^{73}$ e Jobst et al em $2009^{74}$ demonstraram em seus estudos que o endotélio não preveniu o crescimento intimal em artérias de coelhos e ratos danificadas por balões de angiografia.

\subsubsection{Hiperplasia intimal}

Histologicamente, a hiperplasia intimal é um acúmulo de células musculares lisas e matriz extracelular no interior da porção subendotelial de uma parede do vaso. Uma lesão arterial inicial estimula a proliferação de células musculares lisas dentro da camada média que é seguida por migração dessas células para a camada íntima ${ }^{75}$.

Em cirurgias de substituição de função vascular as células musculares lisas migram da artéria nativa para a superfície interna da prótese ou do enxerto promovendo o estreitamento luminal ${ }^{76}$. 
Apesar das discordâncias quanto à relação endotelização e hiperplasia intimal, está claro que a presença desse crescimento é desfavorável à patência de próteses e enxertos ${ }^{72}$ e a busca pelo controle desse crescimento acaba por ser o foco de diversos estudos.

Um deles é o uso de arginina como suplemento oral, que demonstrou ser efetiva na redução dos radicais livres e no aumento da produção de óxido nítrico. Esses fatores preservaram a camada endotelial nos enxertos de veia, porém o volume de células musculares lisas não foi reduzido ${ }^{11}$.

Outra proposta para diminuir a hiperplasia intimal é a tensão de cisalhamento (shear stress) no endotélio ${ }^{77}$, que corresponde à força tangencial ( $\tau)$ que o fluxo sanguíneo realiza na superfície do endotélio vascular ${ }^{78}$.

Essa tensão é medida em dinas por centímetro quadrado, que é força necessária para provocar uma aceleração de um centímetro por segundo quadrado em um corpo de massa igual a um grama, e equivale a 10-5 Newtons (N). Artérias e veias recebem diferentes níveis de tensão de cisalhamento, fato esse determinado pelas características da velocidade do fluxo sanguíneo. Uma artéria recebe uma tensão média de 10 a 70 dinas $/ \mathrm{cm}^{2}$, enquanto os valores para veias não passam de 1 a 6 dinas $/ \mathrm{cm}^{2} 79$.

Uma tensão de cisalhamento alta provavelmente promove sobrevida e quietude das células endoteliais, alinhamento dessas células no sentido do fluxo e secreção de substâncias que promovem vasodilatação e anticoagulação $^{77,80-82}$. Em contrapartida, uma tensão de cisalhamento baixa pode promover a proliferação endotelial e apoptose, mudança no formato das 
células, e secreção de substâncias que promovem vasoconstrição, coagulação e agregação plaquetária ${ }^{78}$.

Meyerson et al em $2001^{77}$ foram alguns dos pesquisadores que comprovaram essa teoria através de um estudo com coelhos que foram submetidos a procedimentos cirúrgicos de implantação de remendo de veia na artéria carótida. Nos remendos que foram submetidos à baixa tensão $\left(<2\right.$ dinas $\left./ \mathrm{cm}^{2}\right)$ a proliferação de células musculares foi muito maior do que nos remendos que receberam tensões de cisalhamento mais altas, o que gerou, consequentemente, maior hiperplasia intimal.

\subsection{Biomateriais:}

Segundo Consensus Conference of the European Society for Biomaterials $^{83}$, um biomaterial é "todo material não vivo usado em um artefato médico, visando à interação com sistemas biológicos". E biocompatibilidade é "a capacidade de um material, em uma aplicação específica, induzir no hospedeiro uma resposta adequada".

Essa resposta adequada exige do hospedeiro, quando se trata de próteses vasculares, uma resistência à formação de trombos e infecções bacterianas $^{25}$, porém o material deve apresentar uma série de características para que possa ser considerado biocompatível (tabela 1). 
Tabela 1 - Características de uma prótese vascular ideal

Biocompatibilidade

Atóxico

Não alergênico

Não induzir malignidade

Causar mínimos traumas aos vasos sanguíneos

Não trombogênico

\section{Complacência}

Flexível, elástico e sem dobras

Resistente à hiperplasia intimal

\section{Fácil processamento}

Propriedades físicas e químicas adequadas

Durabilidade mecânica

Disponibilidade em diferentes tamanhos e comprimentos

Fácil de suturar

Esterilizável

\section{Opcional}

Baixo custo

Fonte: Teebken e Haverich (2002) ${ }^{84}$

Um dos maiores desafios da ciência dos biomateriais é a obtenção de biomateriais poliméricos hemocompatíveis. Quando o biomaterial entra em contato com o sangue, reações bioquímicas que induzem mudanças nas funções fisiológicas do sangue são iniciadas acionando o sistema de coagulação sanguínea, com subsequente formação de trombos na superfície do biomaterial ${ }^{85}$.

Diversos são os tipos de biomateriais, cada um com sua determinada finalidade de aplicação. Os polímeros, por exemplo, pertencem à classe mais diversificada dos biomateriais ${ }^{86}$. 


\subsubsection{Polímeros}

Polímero (do grego poli= muitos; mero= partes) é definido por "macromolécula formada por repetições de átomos ou grupo de átomos (monômeros) através da reação chamada polimerização"87.

Os polímeros podem ser classificados quanto à ocorrência (natural ou sintético) e quanto ao comportamento mecânico (plásticos, fibras ou elastômeros/borrachas) $)^{86}$.

Os plásticos são materiais que contém, como principal componente, um polímero orgânico sintético e se caracterizam pela capacidade de se tornarem fluidos e, portanto são capazes de serem moldados por ação de calor e pressão ${ }^{88}$. Fibra é um corpo que tem uma razão elevada entre o comprimento e as dimensões laterais e é composto principalmente por macromoléculas lineares, orientadas longitudinalmente ${ }^{89}$. Elastômeros ou borrachas são macromoléculas que exibem elasticidade em longa faixa em temperatura ambiente $^{86}$.

Com relação à fusibilidade, os polímeros podem ser termoplásticos, ou seja, capazes de se tornarem fluídos a certa temperatura e depois retornarem à forma anterior quando há decréscimo na temperatura e podem ser termorrígidos, ou seja, quando não é possível essa transformação, pois suas macromoléculas estão unidas entre $\mathrm{si}^{90}$.

Os polímeros também podem ser classificados de acordo com suas estruturas químicas. O nome dado ao polímero é originado da família química a qual pertence. Por exemplo, o tereftalato de etileno (poliéster) é resultado da 
polimerização do ácido tereftálico com glicol etilênico. Poliamidas são então originadas de ligações amida na cadeia principal. Quando um polímero é originado por mais de um tipo de mero é chamado copolímero, por exemplo, etileno e propileno ${ }^{91}$.

\subsubsection{Silicones (PDMS)}

Pela analogia com as cetonas, em 1904 o nome silicone foi dado por Kipping aos compostos de fórmula genérica $\mathrm{R}_{2} \mathrm{SiO}^{92}$. Quando $\mathrm{R}$ é o radical metila tem-se então polidimetilsiloxano, fórmula mais comum do silicone (figura 1). Os radicais metila da cadeia também podem ser substituídos por muitos outros grupos, tais como fenila, vinila ou trifluoropropila ${ }^{93}$.

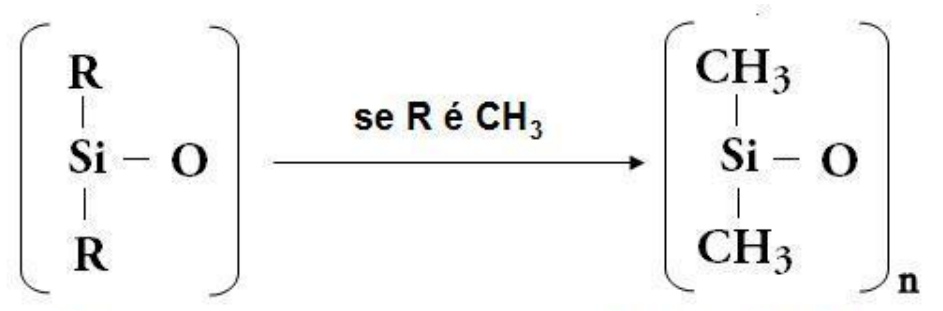

Siloxano

Polidimetilsiloxano

Figura 1- Fórmula do polidimetilsiloxano (PDMS)

Assim como o PTFE e o Dacron, os silicones também são polímeros sintéticos, porém com esqueletos inorgânicos silício-oxigênio com grupos laterais orgânicos ligados aos átomos de silício $(\mathrm{Si})^{94}$.

Desde a década de 1960 o silicone tem sido utilizado na área médica ${ }^{95,96}$ e, devido a suas características, tornou-se um dos materiais mais utilizados em 
substituições protéticas em outros territórios, como o consagrado uso em reconstruções mamárias ${ }^{97}$. Para a veiculação de substâncias para uso endovenoso, sob a forma de variados tipos de cateteres, seu uso é também disseminado e universalmente aceito ${ }^{98,99}$.

As características que tornam o material atraente para estes usos são excelente estabilidade térmica, boas propriedades umectantes, inércia fisiológica, excelente bioestabilidade a longo-prazo e baixa trombogenicidade ${ }^{94,100,101}$. Entretanto, o silicone em sua configuração habitual é hidrofóbico e não poroso, e o fato de ser inerte e provocar baixa reação tecidual o fez ser considerado desvantajoso quando o pensamento vigente era o de que as próteses vasculares necessitavam o máximo de integração tecidual, e que a invasão celular a partir dos poros do enxerto pudesse promover a endotelização da superfície interna dos tubos protéticos. Um estudo realizado no início da experiência com próteses vasculares, que utilizou próteses de silicone em pequeno grupo de animais (dez cães), e que mostrou alto índice de oclusões em seguimento tardio, sepultou as perspectivas em relação ao uso desse material por vários anos seguidos ${ }^{102}$.

Além desse fato, características físicas do silicone, assim como sua forma de confecção e manuseio, tenham tornado seu uso restrito no inicio da experiência com próteses vasculares. Entre as características físicas que necessitam adaptações para uso como próteses vasculares estão a baixa tolerância ao rasgo e alto coeficiente de atrito ${ }^{94}$.

Após muitos anos sem estudos que dessem continuidade ao uso do silicone em próteses vasculares, Bass et al em $1993^{103}$ e Lumsden et al em 
$1996^{58}$ aprovaram seu uso através de um estudo onde tubos de PTFEe eram revestidos com PDMS e apresentaram bons resultados com relação à patência das próteses. Okoshi et al ${ }^{104}$ testaram diferentes tipos de porosidade em próteses de poliuretano misturadas com PDMS de $1,5 \mathrm{~mm}$ de diâmetro implantadas em aortas de ratos. E Drasler et al ${ }^{105}$ demonstraram que o silicone pode ser um bom material para enxertos para acesso dialítico.

$\mathrm{Na}$ tentativa de avaliar as propriedades mecânicas do PDMS LarenaAvellaneda et al ${ }^{106}$ revestiram próteses de poliéster com PDMS e apresentaram resultados comparáveis com as próteses de PTFE e poliéster sem revestimento, porém não realizaram estudo com modelos animais.

\subsection{Modelos animais para cirurgia vascular:}

Modelos animais são utilizados para simular anatomia, fisiologia e patologia humana ${ }^{107}$. O início das pesquisas com animais provavelmente iniciou-se com Hipócrates (450 a.C) que relacionava o aspecto de órgãos humanos doentes com o de animais, com finalidades claramente didáticas ${ }^{108}$.

Muito tempo depois da proibição da dissecção humana em Roma em 150 a.C., Claudio Galeno, um médico grego que morou em Roma, foi quem deu início aos estudos em animais por volta de 200 d.C. ${ }^{109}$. Galeno ficou conhecido como um dos precursores das ciências médicas experimentais, realizando vivissecções com objetivos experimentais, ou seja, de testar variáveis através de alterações provocadas nos animais ${ }^{108}$. 
Atualmente, a escolha do animal para realização de uma pesquisa depende da natureza da engenharia de tecido que está sendo testada. Os fatores que precisam ser considerados incluem pré-requisitos técnicos de implantação, tamanho e disponibilidade do animal, calibre e tamanho do enxerto, custos e considerações éticas ${ }^{107,110}$.

Além destes critérios citados, a mortalidade do modelo animal no pósoperatório deve ser considerada. Intubação endotraqueal em ovelhas (Ovis aries), por exemplo, é extremamente difícil devido a sua anatomia. A não ventilação somada ao alto risco de regurgitação durante o procedimento anestésico levam a uma alta taxa de mortalidade dessa espécie ${ }^{108}$.

Complicações anestésicas em coelhos (Oryctolagus cuniculus) representam taxa de mortalidade de aproximadamente $30 \%$, assim como cães (Canis lupus familiaris) e porcos (Sus domesticus), porém também tendem a desenvolver paraplegia após clampeamento de aorta infrarenal. Apesar disto, os coelhos têm a vantagem de ter um tamanho anatômico razoável e um menor custo em termos de aquisição e manutenção ${ }^{111}$.

Com relação à coagulação e sistema fibrinolítico, os bezerros (Bos taurus) e primatas não humanos são mais semelhantes ao homem do que cães e porcos $^{112}$. Porém os primatas acabam sendo menos utilizados devido a considerações éticas ${ }^{113}$.

Apesar de ser anatômica e fiosiologicamente semelhante ao homem, o modelo porcino é pouco escolhido para testes de novos condutos vasculares. Isto porque, apesar de baixo custo no momento da aquisição, sua manutenção 
é onerosa e seu crescimento é acelerado, podendo ganhar mais de 70 quilos em dois meses ${ }^{110}$.

Nenhum modelo animal é capaz de reproduzir com perfeição todos os critérios exigidos para o desenvolvimento de uma prótese ideal, porém alguns modelos são capazes de desenvolver bem alguns desses critérios ${ }^{114}$.

Dentre os animais de pequeno porte, o coelho e o camundongo (Mus musculus) são os modelos mais escolhidos para estudos de condutos vasculares de pequeno calibre, principalmente devido ao baixo custo na aquisição e manutenção. O coelho, porém, vem sendo mais indicado para esses estudos, pois é mais semelhante ao homem que o rato, quanto à coagulação, endotelialização, patência e trombogenicidade ${ }^{107,115}$.

O desenvolvimento de variantes transgênicas de modelos atualmente disponíveis podem ampliar as opções no futuro, como por exemplo camundongos imunodeficientes para estudo de enxertos de pequeno calibre ${ }^{116}$. No entanto, uma valorização das características individuais de cada espécie é de extrema importância para a boa execução de experimentos ${ }^{112}$. 


\subsection{Hipótese deste trabalho}

Considerando a busca em aberta pela prótese vascular ideal e que o polidimetilsiloxano é um material que promove poucas reações teciduais, este trabalho pretende propor um modelo experimental para testar a hipótese de que o PDMS é um substituto arterial adequado para vasos de pequeno calibre. 


\section{Objetivos}

\subsection{Geral:}

Analisar tubo de PDMS com reforço de poliéster implantado em aorta de coelhos como material alternativo para prótese vascular.

\subsection{Específicos:}

- Avaliar a patência das próteses através de fluoroscopia;

- Avaliar a condição de implante cirúrgico;

- Avaliar o comportamento macroscópico biológico do implante;

- Analisar o modelo experimental proposto. 


\section{Métodos}

\subsection{Cálculo amostral:}

Para o cálculo do tamanho da amostra necessário utilizamos os dados do trabalho de Nordestgaard e colaboradores ${ }^{117}$, que estudaram a prevalência de complicações tromboembólicas em coelhos submetidos à implantação de prótese arterial de politetrafluoroetileno (PTFE) em aorta. A taxa de patência em três meses para a prótese de $2 \mathrm{~mm}$ de diâmetro interno foi de $24 \%$.

Considerando-se uma distribuição binomial (patência versus nãopatência), pudemos calcular o tamanho, $n$, da amostra de acordo com a equação:

$$
n=(1.96)^{2} \frac{p(1-p)}{\varepsilon^{2}}
$$

onde $p$ é a prevalência esperada do evento mais raro $(24 \%)$ e $\varepsilon$ é a precisão absoluta (10\%), o que resulta em 70 animais que sobrevivam por pelo menos 3 meses. 


\subsection{Grupo de estudo:}

Os procedimentos cirúrgicos foram realizados em coelhos domésticos (Oryctolagus cuniculus) na disciplina de Técnica Cirúrgica da Faculdade de Medicina da Universidade de São Paulo. Os animais foram fornecidos pelo biotério da mesma faculdade e sexo foi definido pelo próprio biotério.

Este estudo foi realizado com autorização do comitê de ética da Faculdade de Medicina da Universidade de São Paulo.

Em cada animal foi implantada prótese tubular feita de PDMS (silicone) com reforço de tecido de poliéster na aorta infrarrenal.

\subsection{Próteses sintéticas:}

As próteses foram confeccionadas segundo patente de número $\mathrm{PI}$ 0704867-0 de De Luccia e De Luccia $^{118}$. O silicone líquido de grau médico foi curado sobre mandril metálico no qual era colocado a tela de tecido a ser ensaiada a fim de aumentar a tolerância ao rasgo do silicone durante 0 implante cirúrgico (figura 2). Para que a cura ocorresse de maneira uniforme o mandril foi mantido em movimento rotatório inicialmente em temperatura ambiente e posteriormente em estufa em temperatura pós-cura de $110^{\circ} \mathrm{C}$ por 30 minutos. As próteses de PDMS apresentavam, então, formato tubular, parede de 0,4mm e diâmetro interno de $4 \mathrm{~mm}$ (figura 3). 


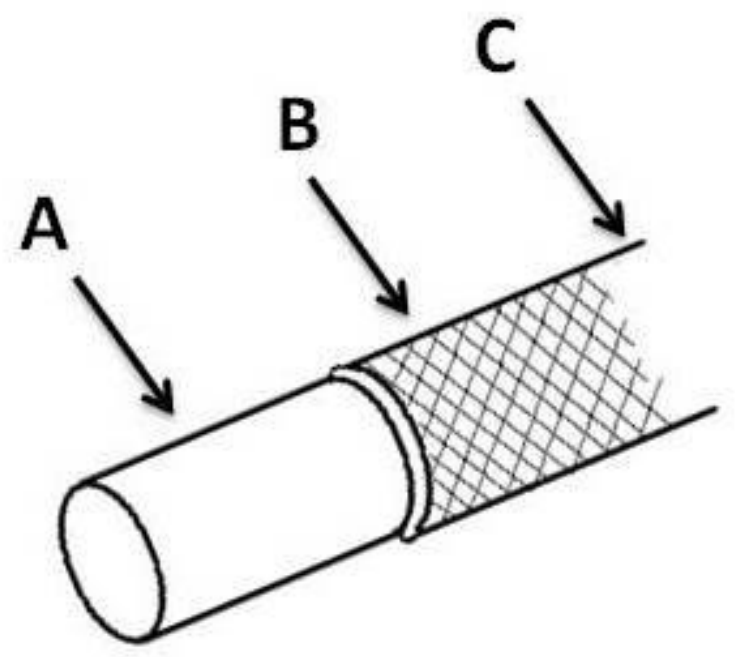

Figura 2 - (A) mandril metálico, (B) tela de tecido de poliéster e (C) silicone

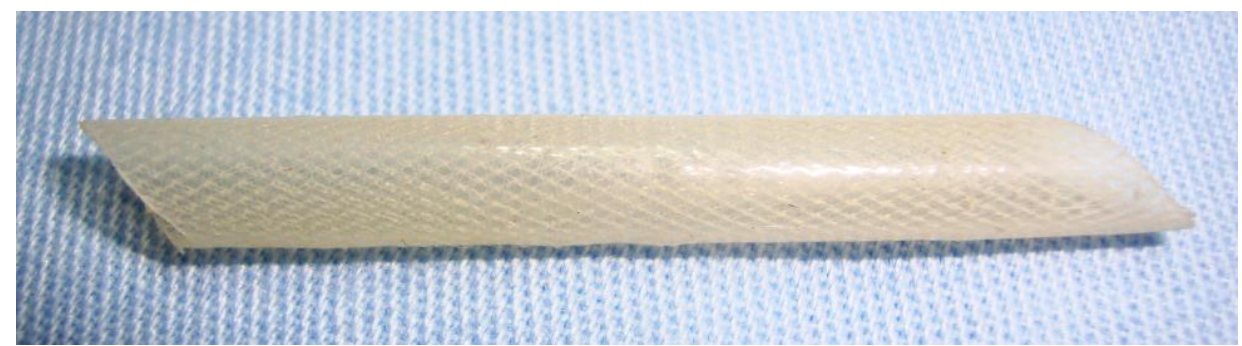

Figura 3 - Tubo de polidimetilsiloxano

\subsection{Procedimentos anestésicos:}

Os procedimento cirúrgicos de implante de prótese vascular foram feitos sob anestesia geral. As doses foram administradas de acordo com o peso de cada coelho, sendo que a indução anestésica foi realizada com Xilazina $2 \%$ (5 $\mathrm{mg} / \mathrm{kg}$ ) e Cetamina 10\% (35 mg/kg) por via intra-muscular e a manutenção com as mesmas drogas por via intravenosa de acordo com as necessidades ${ }^{119}$. Durante os procedimentos cirúrgicos os animais receberam solução fisiológica 
(cloreto de sódio 0,9\%) através de cateter 22G canulado na veia marginal da orelha.

\subsection{Técnica cirúrgica:}

Por via transperitoneal, através de laparotomia mediana, a aorta infrarrenal foi exposta e dissecada em aproximadamente 3 a $4 \mathrm{~cm}$ (figura 4). Foi administrada heparina sódica na dose de $200 \mathrm{U} / \mathrm{kg}$ por via intravenosa antes do clampeamento da aorta.

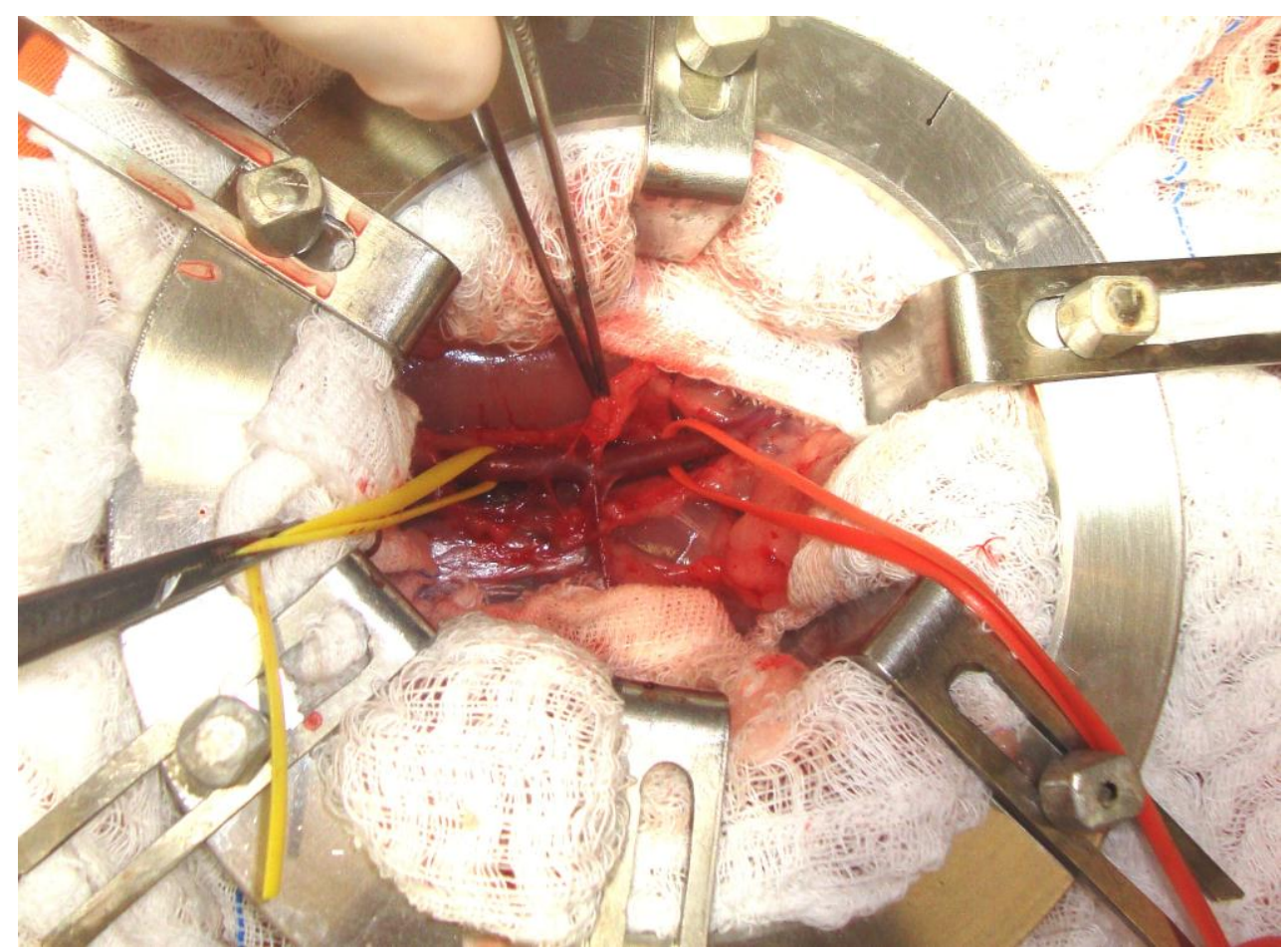

Figura 4 - Aorta infrarrenal dissecada

A ligadura e secção de algumas artérias lombares próximas à região dissecada foram evitadas quando possível para evitar paraplegia no pósoperatório. 
As anastomoses do tubo de PDMS na aorta foram feitas por técnica término-lateral, com fios de polipropileno agulhado, tamanho 7-0 e em pontos contínuos. Foi desenvolvido afastador autoestático próprio para a realização deste estudo o que preveniu evisceração (figura 5). Tais anastomoses foram feitas em duas etapas (proximal e distal). Quando terminada a anastomose proximal o fluxo sanguíneo foi liberado por alguns minutos, restaurando a perfusão dos membros. Dessa maneira se fazia a proteção tecidual através de condicionamento isquêmico.

O tempo de clampeamento da aorta foi aferido nos coelhos operados, somando o tempo do primeiro clampeamento com 0 segundo, desconsiderando-se, portanto, o tempo de condicionamento isquêmico.

Após o término das anastomoses os clamps vasculares foram removidos e foi verificado pulso distal ao tubo. Foi feita ligadura da aorta, entre as anastomoses, com fio de algodão, tamanho 4-0 e então secção da mesma (Figura 6). As suturas das aponeuroses foram realizadas com fio catgut 2-0 e da pele com nylon 2-0.

A sequência operatória está representada pela figura 7 . 


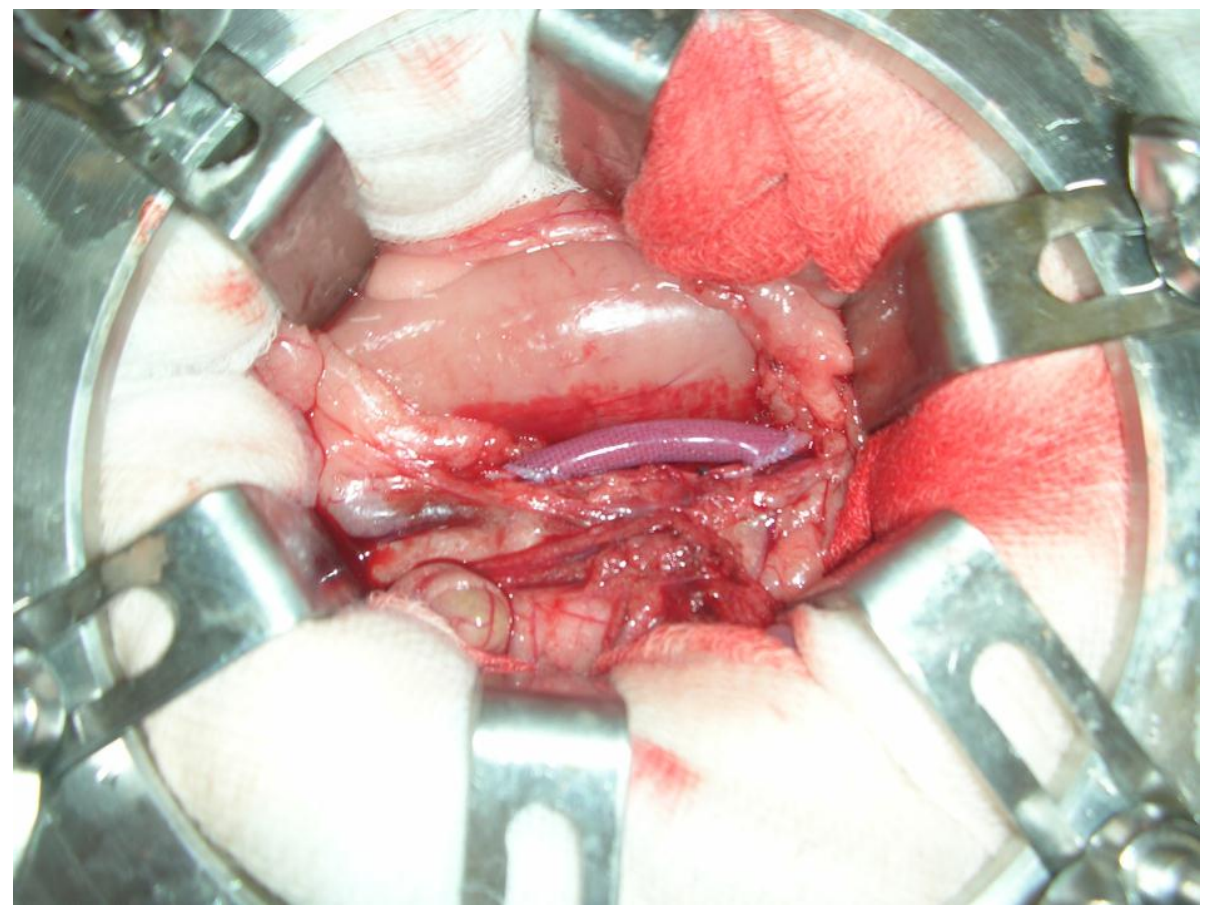

Figura 5 - Prótese de PDMS - anastomose término-lateral e afastador autoestático

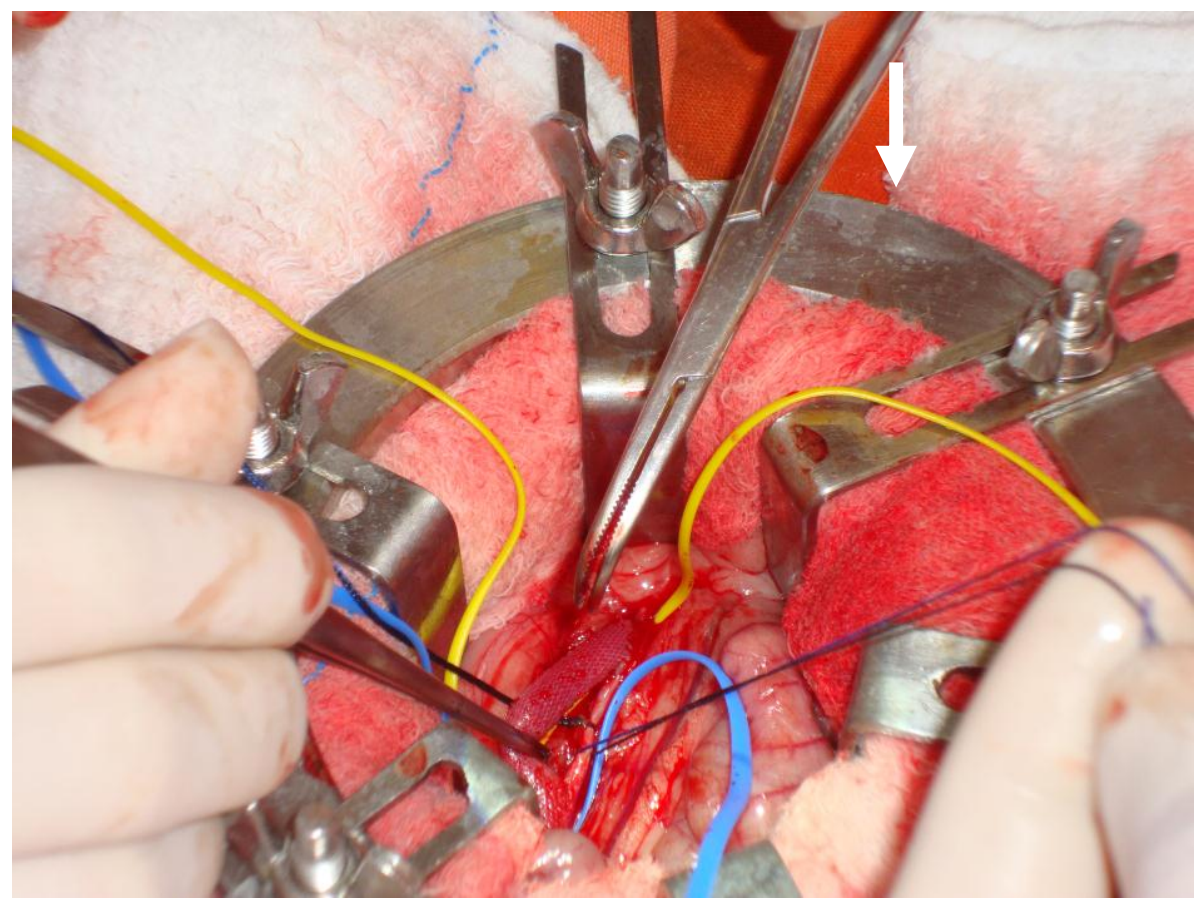

Figura 6 - Ligadura da aorta entre as anastomoses 

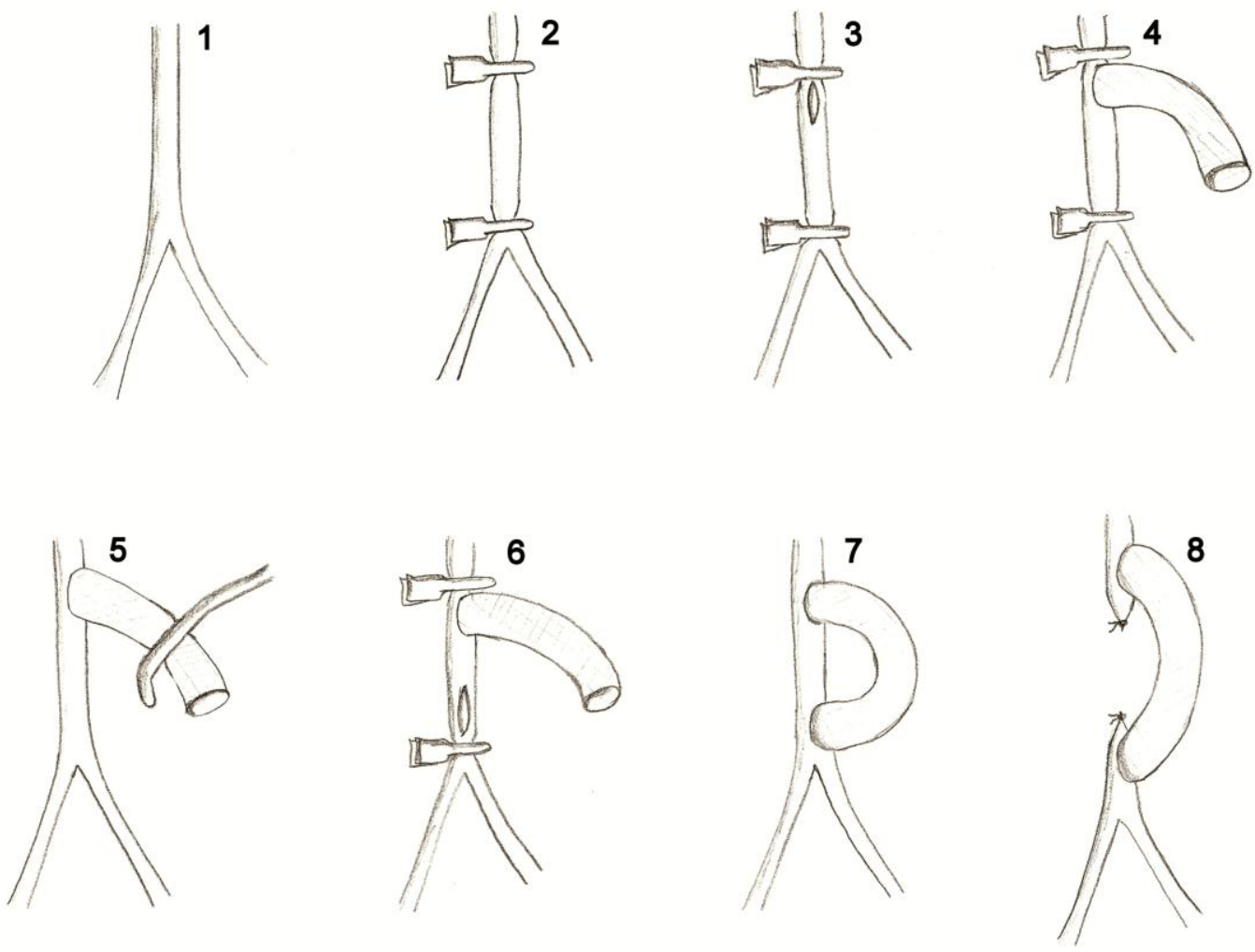

Figura 7 - (1) Aorta infrarrenal, (2) clamps vasculares proximal e distal, (3) incisão longitudinal na aorta, (4) implante proximal do tubo de PDMS, (5) clamp no tubo para condicionamento isquêmico, (6) incisão distal, (7) tubo de PDMS implantado na aorta já sem os clamps e (8) aorta ligada e seccionada após as anastomoses.

\subsection{Avaliações pós-operatórias:}

Após os procedimentos cirúrgicos os animais foram encaminhados para biotério e mantidos por período de até 150 dias. Receberam medicação analgésica e anti-inflamatória de acordo com as recomendações de médico veterinário.

Os animais foram avaliados clinicamente e os que apresentaram paraplegia no pós-operatório foram eutanasiados com anestesia (mesmo protocolo anterior) e cloreto de potássio 19,1\% intravenoso. 
MÉTODOS

\subsection{Avaliações das próteses:}

As próteses foram avaliadas através de fluoroscopia da aorta por contraste retrógrado. Para tal técnica os animais foram anestesiados com 0 mesmo protocolo usado no procedimento cirúrgico e a artéria femoral foi dissecada, seccionada longitudinalmente e cateterizada com cateter de Silastic® acoplado à agulha de tamanho $40 \times 12$.

Após cateterização da artéria femoral, foi aplicado contraste Reliev $60 \%$ (diatrizoato de meglumina) e realizado fluoroscopia da aorta (figura 8) com equipamento OEC Diasonics ${ }^{\circledR}$. As próteses foram classificadas de acordo com sua patência, sendo: patentes (com passagem de fluxo sanguíneo) e ocluídas (sem passagem de fluxo). As próteses patentes foram subdivididas em graus de estenose, ou seja, grau de diminuição da luz protética. Para essa medição foi calculada a porcentagem do diâmetro da prótese em relação ao diâmetro das aortas proximal e distal através de software disponível no equipamento de fluoroscopia (figura 9).
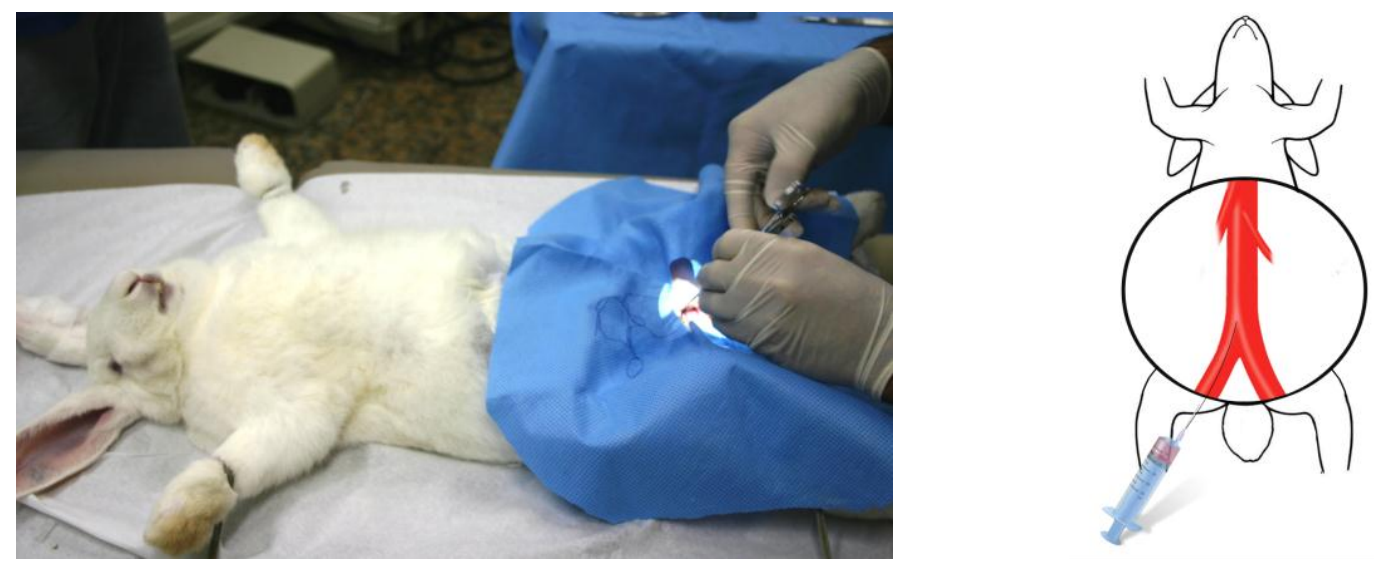

Figura 8 - Cateterização da artéria femoral do coelho para aplicação de contraste e realização da fluoroscopia 


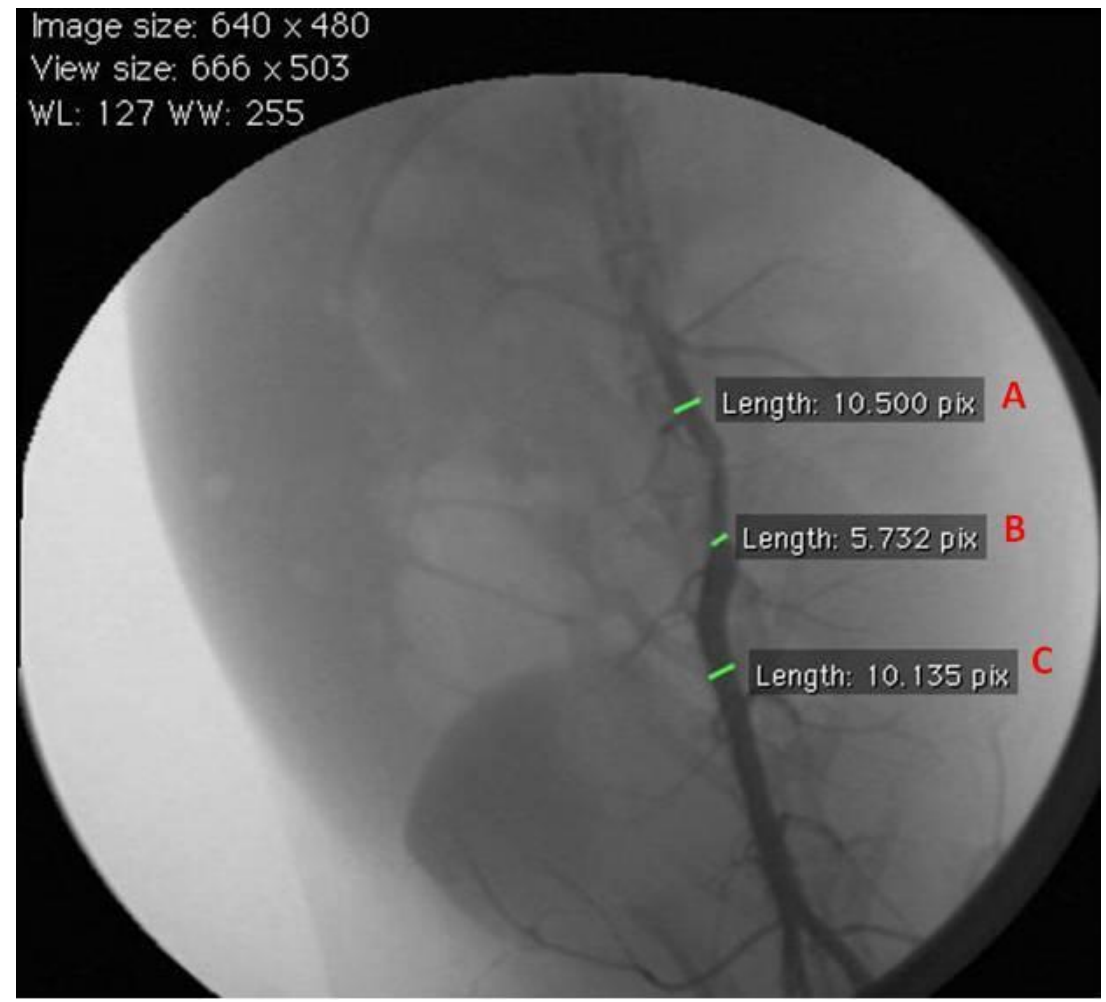

Figura 9 - grau de estenose da prótese. (A) Medida do diâmetro da aorta proximal à prótese, (B) medida do diâmetro da prótese e (C) medida do diâmetro da aorta distal à prótese.

Após o término dos procedimentos e ainda anestesiados os animais foram eutanasiados com cloreto de potássio $19,1 \%$ e os corpos destinados de acordo com a rotina da disciplina de técnica cirúrgica.

As próteses foram retiradas após a eutanásia e as peças encaminhadas para microscopia eletrônica de varredura de maneira amostral (figura 10).

A microscopia foi realizada por equipamento da marca Philips, modelo XL30. 


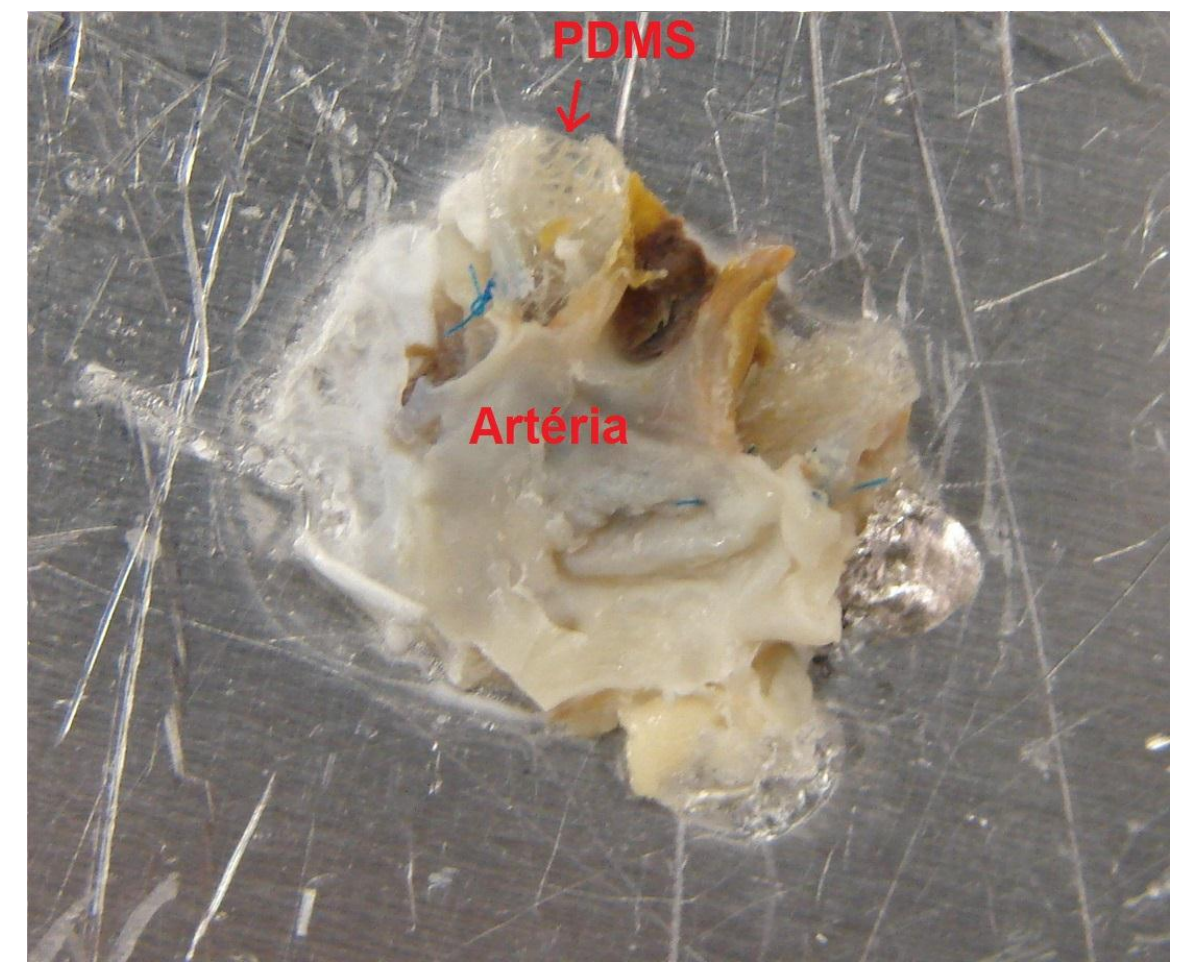

Figura 10 - Peça de PDMS removida após fluoroscopia

\subsection{Análises estatísticas:}

A distribuição temporal das oclusões foi analisada pela função de sobrevida $^{120,121}$. Seja $S(t)$ a proporção de animais na condição patente no instante $t$.

A taxa de oclusão $\lambda(t)$ em cada instante de tempo $t$ pode ser estimada a partir de $S(t)$ como:

$$
\lambda(t)=-\frac{d}{d t} \log [S(t)]
$$

O risco cumulativo de oclusão pode então ser calculado como:

$$
\Omega(t)=\int_{0}^{t} \lambda(x) d x
$$


Para associação entre o tempo de clampeamento da aorta e a evolução clínica dos coelhos foi utilizado o teste de variância ANOVA e para a associação do tempo de clampeamento da aorta com a patência das próteses foi utilizado o teste t-Student.

As análises estatísticas foram realizadas com o software SPSS 18.0. 


\section{Resultados}

Foram realizados 64 procedimentos cirúrgicos em grupo de animais com peso médio de $3,7 \mathrm{~kg}$.

\subsection{Característica cirúrgica:}

A parede da prótese teve características de flexibilidade e dureza que permitiram facilidade na passagem da agulha e qualidades de retenção e contenção das linhas de sutura.

Desta forma hemostasia satisfatória foi obtida ao final dos experimentos e a sensação palpatória distal às anastomoses atestou a patência imediatas das próteses nos 64 animais.

\subsection{Avaliação clínica dos animais:}

Dos 64 animais que receberam a prótese, trinta $(46,9 \%)$ apresentaram boa evolução clínica, vinte e três $(35,9 \%)$ morreram e onze $(17,2 \%)$ apresentaram paraplegia de membros posteriores (gráfico 1).

O tempo médio de sobrevida dos animais que morreram foi de dois dias e os com paraplegia foi de 2,45 dias.

Nenhum dos animais apresentou sintomas compatíveis com infecção pósoperatória. 


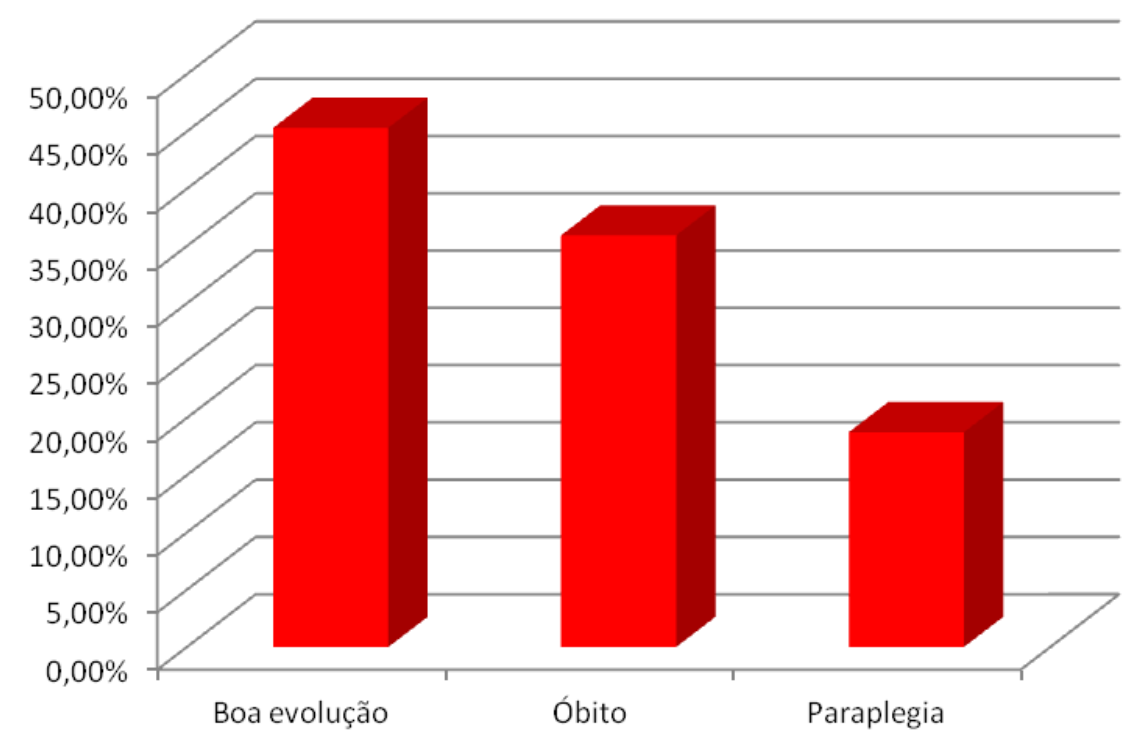

Gráfico 1 - Evolução clínica dos animais com próteses de PDMS.

\subsection{Avaliação das próteses:}

Foram realizadas fluoroscopias em 33 animais. Seis coelhos que apresentaram oclusão aguda (tempo menor que sete dias) foram excluídos do estudo, considerando esse tipo de oclusão característico de erro cirúrgico e não inerente à prótese.

A patência das próteses avaliada pelo método de Kaplan-Meier em 30 dias foi de $87 \%( \pm 6,7)$, em 60 dias foi de $73 \%( \pm 9,3)$, em 90 dias foi de $57 \%$ ( \pm 11$)$ e em 120 dias foi de $48 \%( \pm 12)$ (figura 11 e tabelas 2 e 3 ).

O risco de oclusão pode ser visto na figura 12. 
Tabela 2 - Resumo

\begin{tabular}{cccc}
\hline \multicolumn{3}{c}{ Resumo } \\
\hline $\mathrm{N}$ total & N dos eventos (não & \multicolumn{3}{c}{ Censura } \\
27 & patete) & $\mathrm{N}$ (patente) & Porcentagem \\
\hline
\end{tabular}

Tabela 3 - Sobrevida na condição "patente"

\begin{tabular}{|c|c|c|c|c|c|c|}
\hline \multicolumn{7}{|c|}{ Tabela de sobrevida } \\
\hline & \multirow{3}{*}{ Tempo } & \multirow{3}{*}{ Status } & \multicolumn{2}{|c|}{ Proporção de sobreviventes no } & \multirow{3}{*}{$\begin{array}{l}\mathrm{N} \text { dos eventos } \\
\text { cumulativos }\end{array}$} & \multirow{3}{*}{$\begin{array}{c}\mathrm{N} \text { dos casos } \\
\text { restantes }\end{array}$} \\
\hline & & & & & & \\
\hline & & & Estimativa & Erro padrão & & \\
\hline 1 & 9.000 & 1.00 & .964 & .035 & 1 & 26 \\
\hline 2 & 12.000 & .00 & . & . & 1 & 25 \\
\hline 3 & 13.000 & .00 & . & . & 1 & 24 \\
\hline 4 & 13.000 & .00 & . & . & 1 & 23 \\
\hline 5 & 15.000 & .00 & . & . & 1 & 22 \\
\hline 6 & 16.000 & .00 & . & . & 1 & 21 \\
\hline 7 & 21.000 & 1.00 & .920 & .054 & 2 & 20 \\
\hline 8 & 28.000 & 1.00 & .877 & .067 & 3 & 19 \\
\hline 9 & 28.000 & .00 & . & . & 3 & 18 \\
\hline 10 & 46.000 & 1.00 & .830 & .078 & 4 & 17 \\
\hline 11 & 47.000 & 1.00 & .784 & .086 & 5 & 16 \\
\hline 12 & 51.000 & 1.00 & .738 & .093 & 6 & 15 \\
\hline 13 & 69.000 & 1.00 & .692 & .098 & 7 & 14 \\
\hline 14 & 70.000 & .00 & & . & 7 & 13 \\
\hline 15 & 72.000 & .00 & . & . & 7 & 12 \\
\hline 16 & 72.000 & .00 & . & . & 7 & 11 \\
\hline 17 & 76.000 & 1.00 & . & . & 8 & 10 \\
\hline 18 & 76.000 & 1.00 & .577 & .110 & 9 & 9 \\
\hline 19 & 76.000 & .00 & . & . & 9 & 8 \\
\hline 20 & 82.000 & .00 & . & . & 9 & 7 \\
\hline 21 & 107.000 & .00 & . & . & 9 & 6 \\
\hline 22 & 111.000 & .00 & . & . & 9 & 5 \\
\hline 23 & 118.000 & 1.00 & .481 & .127 & 10 & 4 \\
\hline 24 & 135.000 & .00 & . & . & 10 & 3 \\
\hline 25 & 142.000 & .00 & . & . & 10 & 2 \\
\hline 26 & 145.000 & .00 & . & . & 10 & 1 \\
\hline 27 & 150.000 & 1.00 & .000 & .000 & 11 & 0 \\
\hline
\end{tabular}




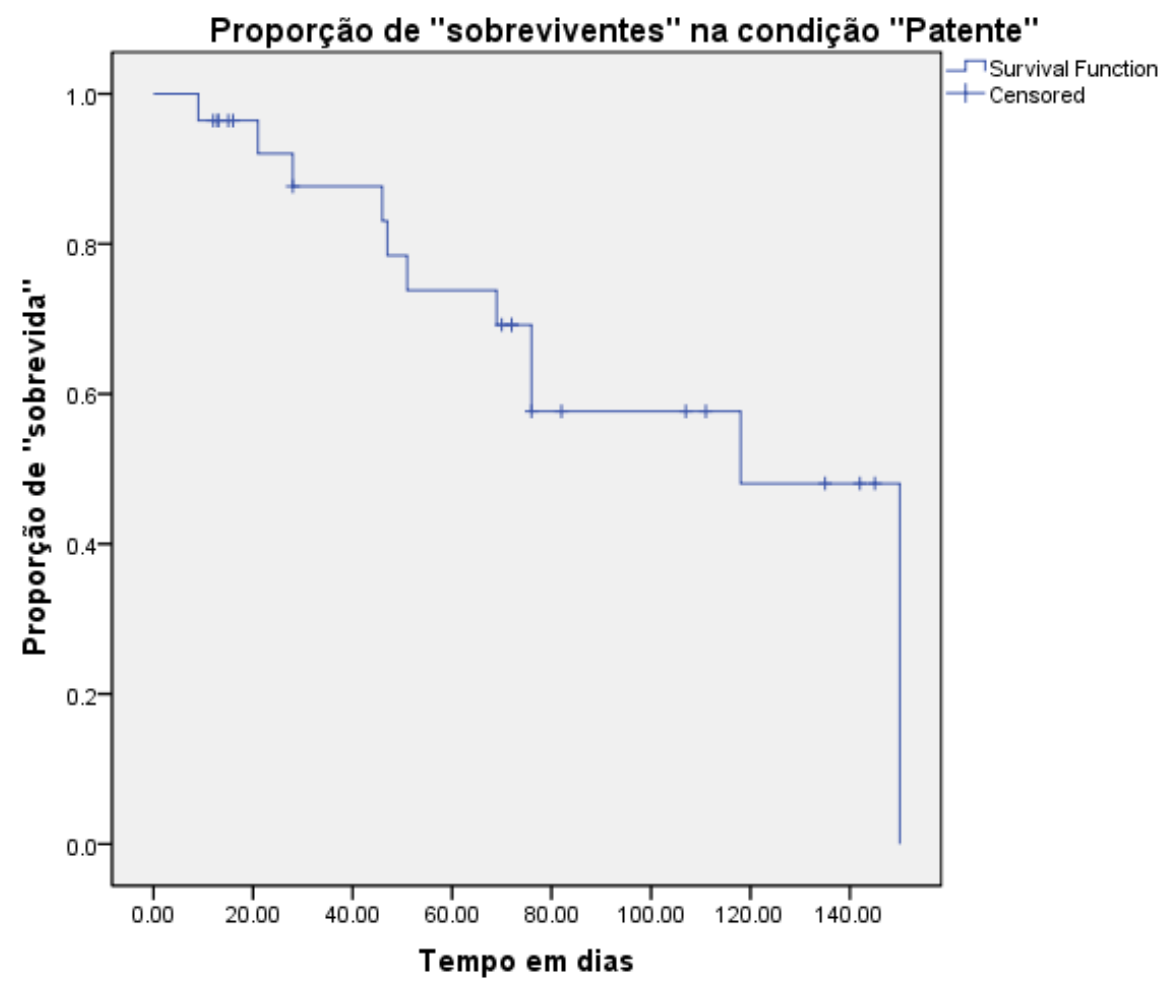

Figura 11 - Proporção de "sobreviventes" na condição patente

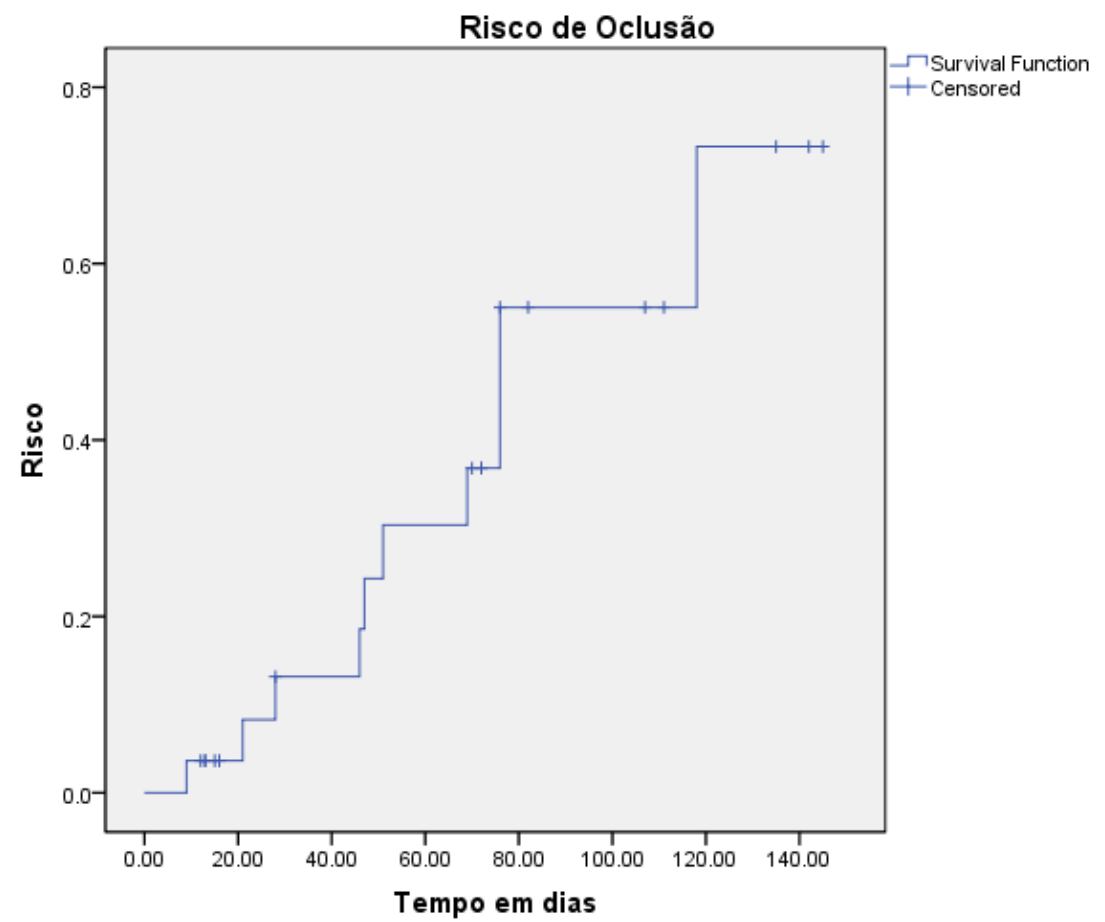

Figura 12 - Risco de oclusão da prótese 
Exemplo de imagem de arteriografia de prótese patente é demonstrada na figura 13.

De acordo com a evolução clínica dos animais foi possível observar nas arteriografias que os coelhos com boa evolução e prótese ocluída apresentaram circulação colateral acentuada vista no exame de imagem (figura 14). Dos coelhos que morreram, em apenas um foi feita fluoroscopia e a próteses encontrou-se ocluída. Esse animal morreu um dia apos a implantação cirúrgica. Nos animais com paraplegia foi possível realizar fluoroscopia em apenas quatro, sendo que três apresentaram prótese ocluída e um patente.

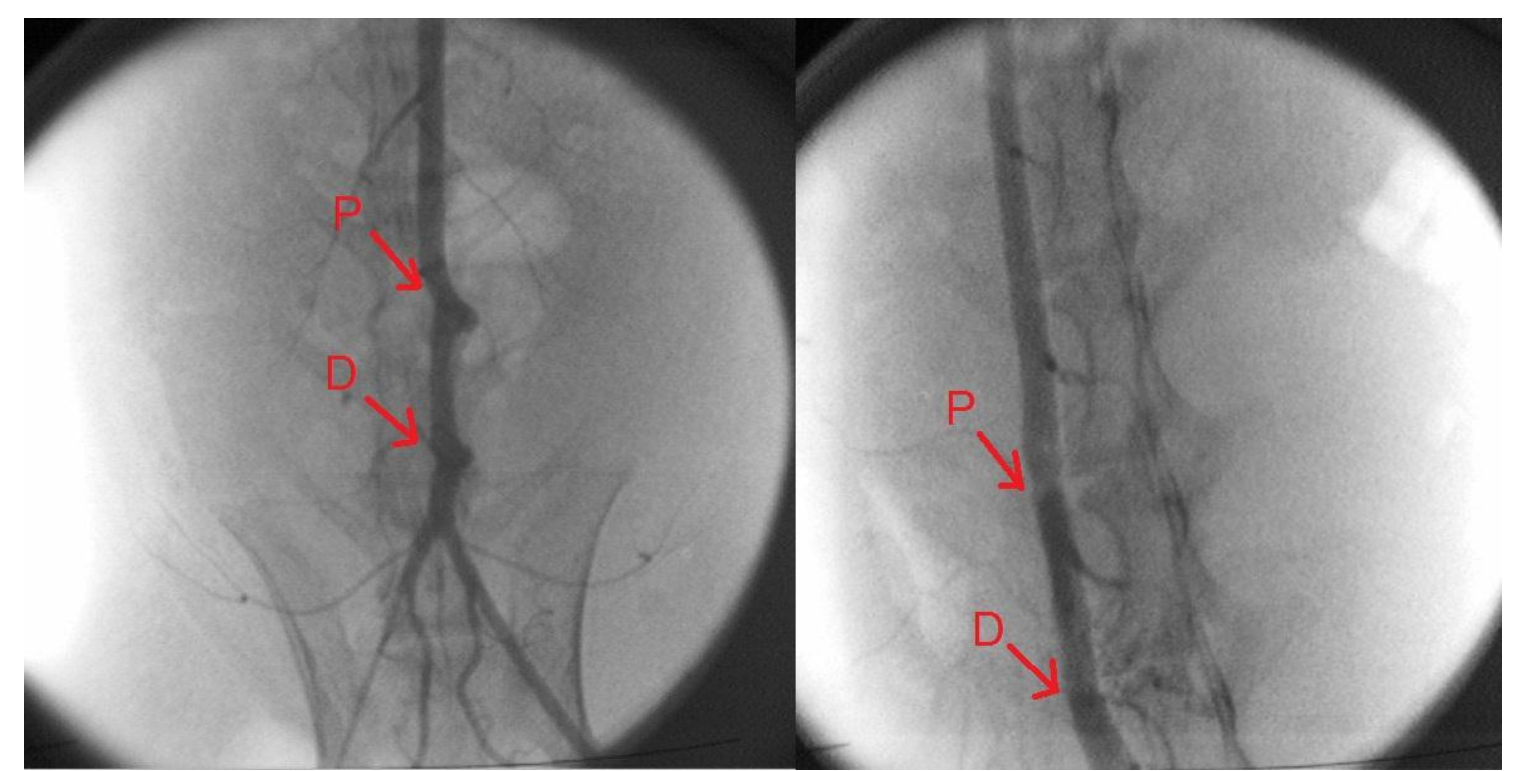

Figura 13 - Arteriografia com 135 dias de pós-operatório com prótese patente em aorta infrarrenal nas projeções ventro-dorsal (esquerda) projeção láterolateral (direita). As setas indicam anastomoses P) proximal e (D) distal. 


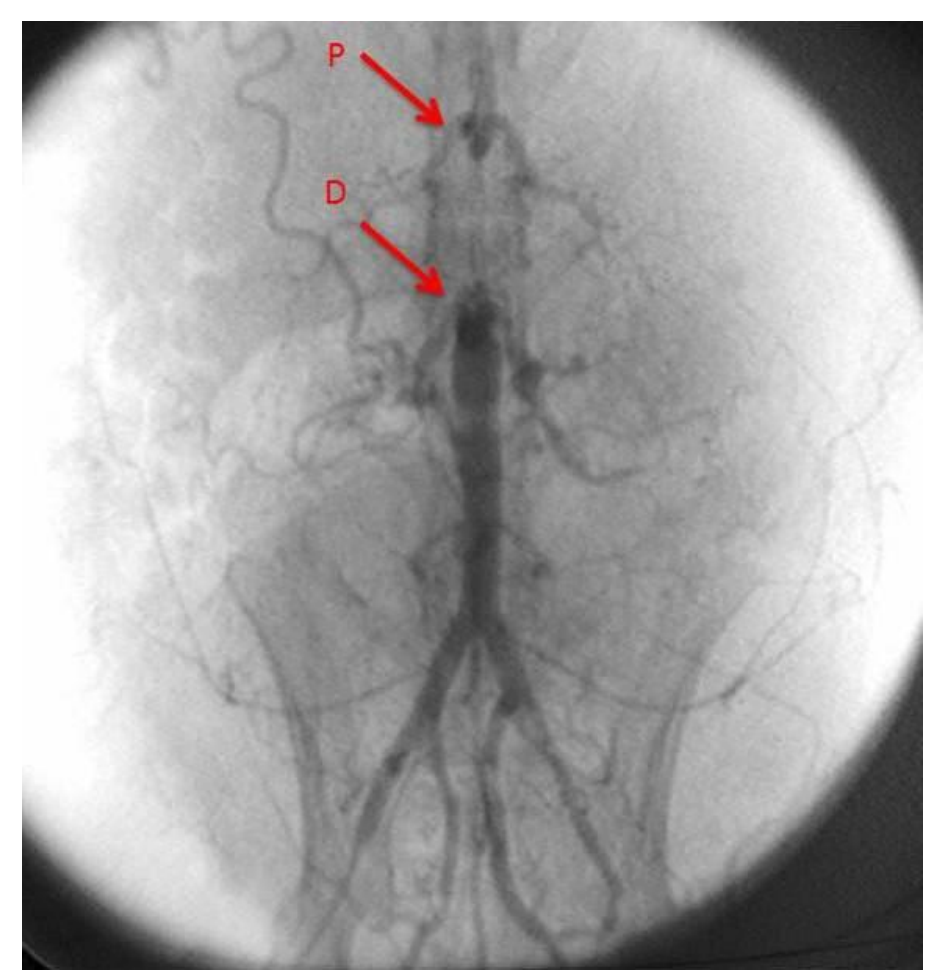

Figura 14 - Circulação colateral acentuada na arteriografia da prótese ocluída com 118 dias. As setas indicam as anastomoses proximal $(P)$ e distal (D)

\subsection{Análise do grau de estenose das próteses patentes}

De acordo com a arteriografia, dos 16 animais com prótese patente, oito (50\%) não apresentaram nenhum grau de estenose, seis $(35,5 \%)$ apresentaram 50\% ou menos de estenose (figura 15) e dois (12,5\%) apresentaram estenose entre 50 e $70 \%$ (figura 16). Nenhum animal apresentou estenose maior que 70\% (gráfico 2). 


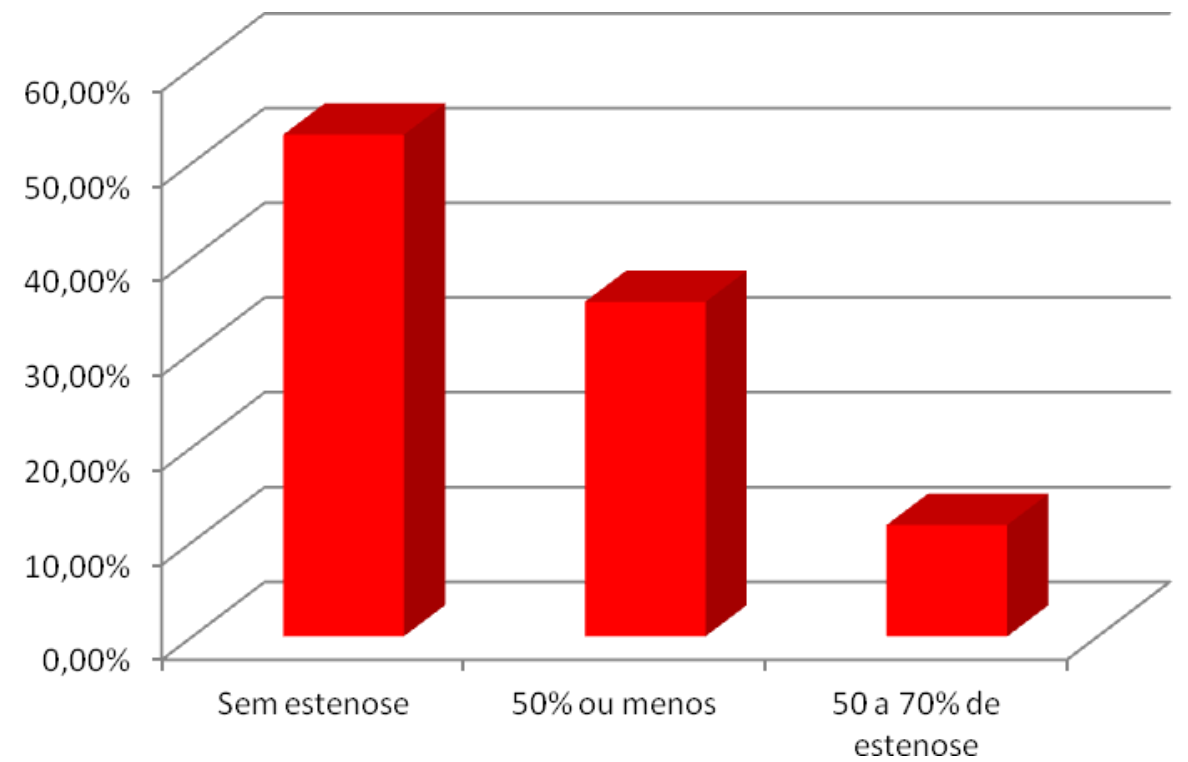

Gráfico 2 - grau de estenose das próteses patentes

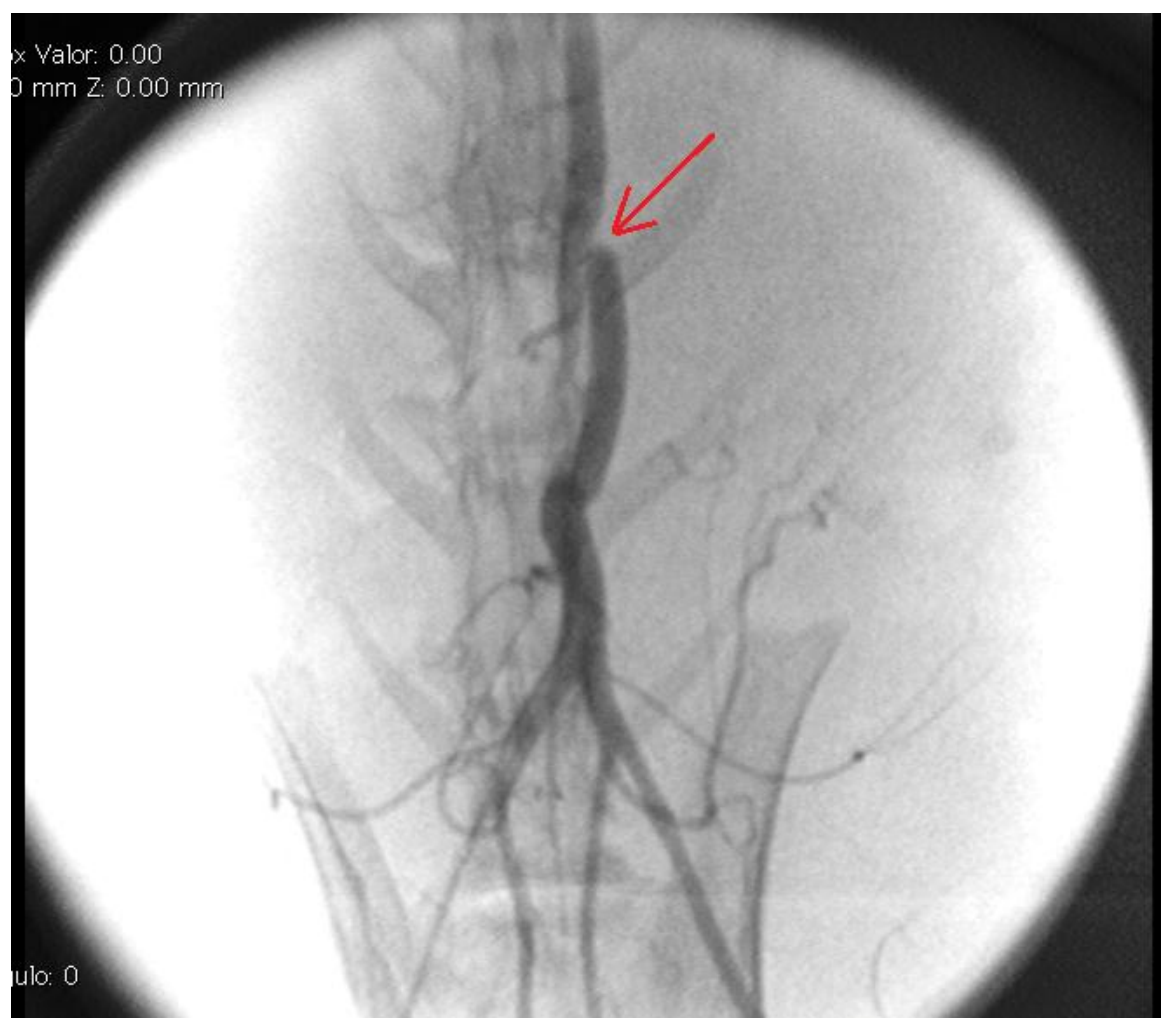

Figura 15 - Fluoroscopia da prótese de PDMS com 78 dias de pósoperatório. A seta indica estenose de menos de $50 \%$ na região de anastomose proximal. 
Figura 16 - Fluoroscopia da prótese de PDMS com 70 dias de pósoperatório. A seta indica estenose de $60 \%$ na região de anastomose proximal.

\subsection{Avaliação do tempo de clampeamento da aorta}

O tempo médio de clampeamento da aorta foi de 52 minutos.

Em uma associação entre o tempo de clampeamento da aorta e a evolução clínica dos animais, não houve diferença significante $(p=0,67)$ (tabela 4).

Tabela 4 - Descrição da associação entre o tempo de clampeamento da aorta e a evolução clínica dos coelhos.

\begin{tabular}{lccccc}
\hline & N & Mínimo & Máximo & Média & $\begin{array}{c}\text { Desvio } \\
\text { padrão }\end{array}$ \\
\hline Boa evolução & 30 & 31.00 & 80.00 & 53.1000 & 11.98088 \\
Óbito & 23 & 20.00 & 78.00 & 50.6522 & 11.89197 \\
Paraplegia & 11 & 40.00 & 81.00 & 54.1818 & 13.59278
\end{tabular}




\begin{tabular}{lccccc}
\hline & N & Mínimo & Máximo & Média & $\begin{array}{c}\text { Desvio } \\
\text { padrão }\end{array}$ \\
\hline Boa evolução & 30 & 31.00 & 80.00 & 53.1000 & 11.98088 \\
Óbito & 23 & 20.00 & 78.00 & 50.6522 & 11.89197 \\
$\begin{array}{l}\text { Paraplegia } \\
\text { N válido }\end{array}$ & 11 & 40.00 & 81.00 & 54.1818 & 13.59278 \\
\hline
\end{tabular}

\begin{tabular}{lccccc}
\multicolumn{5}{c}{ Teste ANOVA (Análise de variância) } \\
\hline & Soma dos & & Média dos & \\
& quadrados & DF & quadrados & F & Significância \\
\hline Entre os grupos & 119.884 & 2 & 59.942 & 0.401 & $\mathbf{0 . 6 7}$ \\
Dentre os grupos & 9121.554 & 61 & 149.534 & & \\
\hline Total & 9241.437 & 63 & & & \\
\hline
\end{tabular}

Em uma associação entre o tempo de clampeamento e a patência das próteses também não houve diferença significante $(t=1,35 ; p=0,18)$.

\subsection{Análise macroscópica das peças}

O tecido fibroso peri-implante apresentou característica de destacar-se facilmente, notando-se um plano de clivagem entre a reação tecidual periprótese e o tubo em estudo.

Não constatou-se dilatação aneurismática do implante ou formação de pseudoaneurisma nas linhas de sutura.

\subsection{Microscopia eletrônica}

As peças encaminhadas para microscopia apresentaram crescimento endotelial a partir do vaso nativo em direção à prótese de PDMS de acordo com as figuras 17 a 20 . 
RESULTADOS

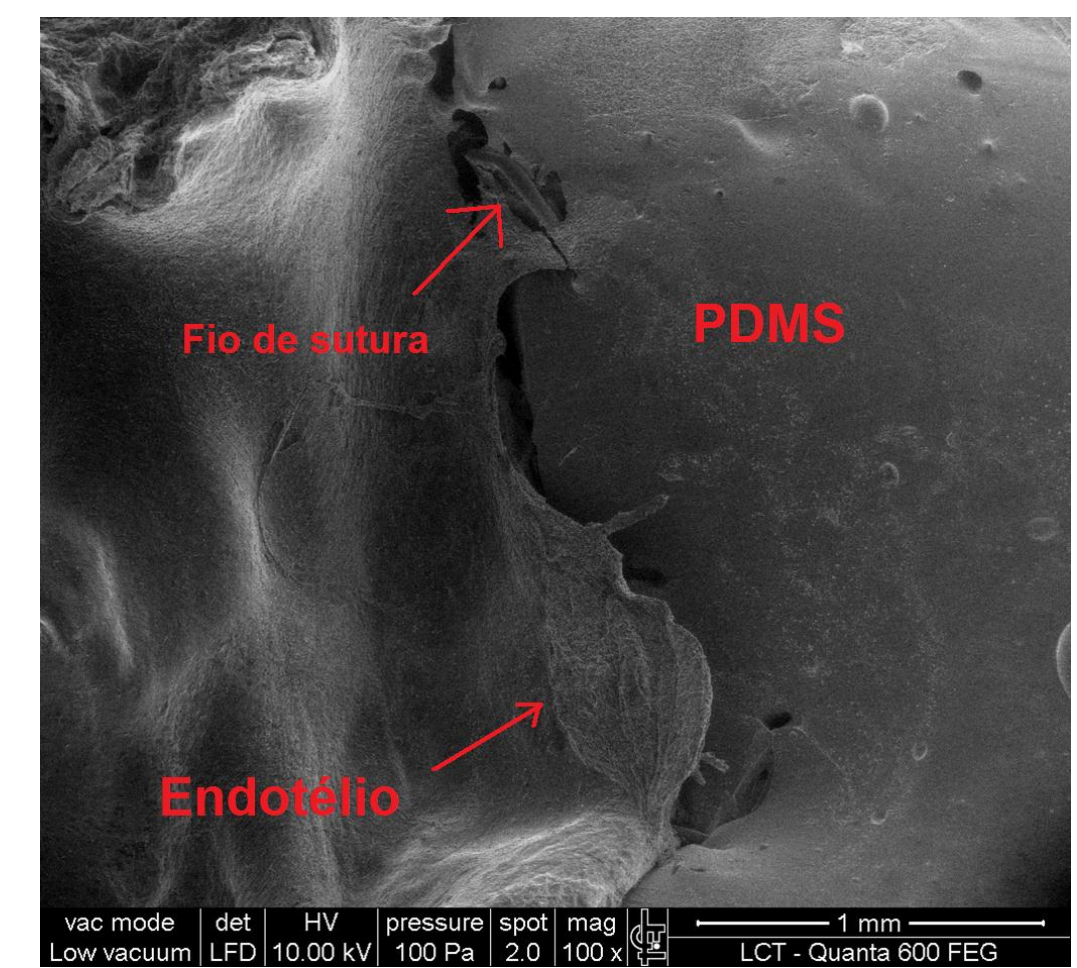

Figura 17 - Visualização de seguimento de tecido endotelial que recobriu parte da prótese de PDMS

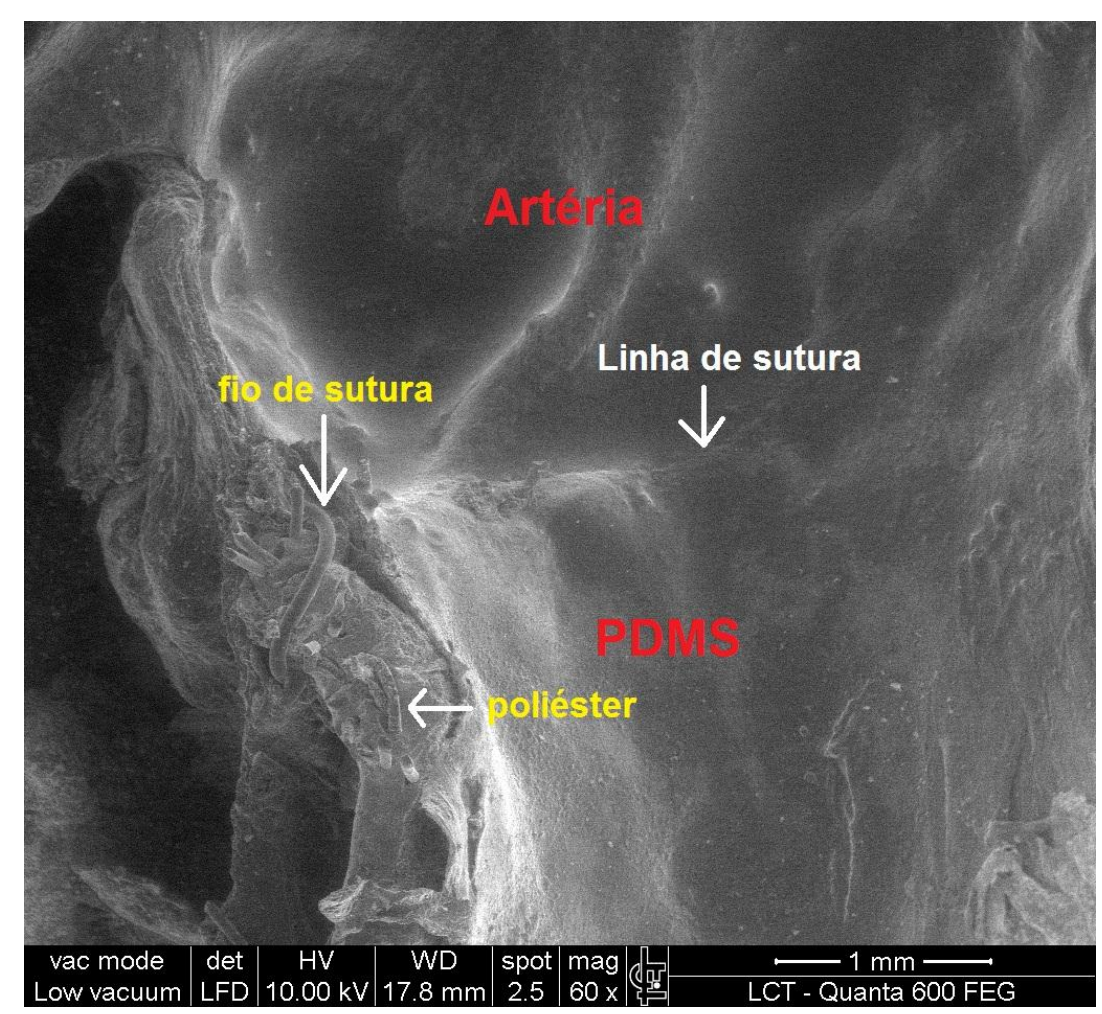

Figura 18 - Microscopia eletrônica de região anastomótica com visualização do fio de sutura, do tecido de poliéster e da linha de sutura. 
RESULTADOS

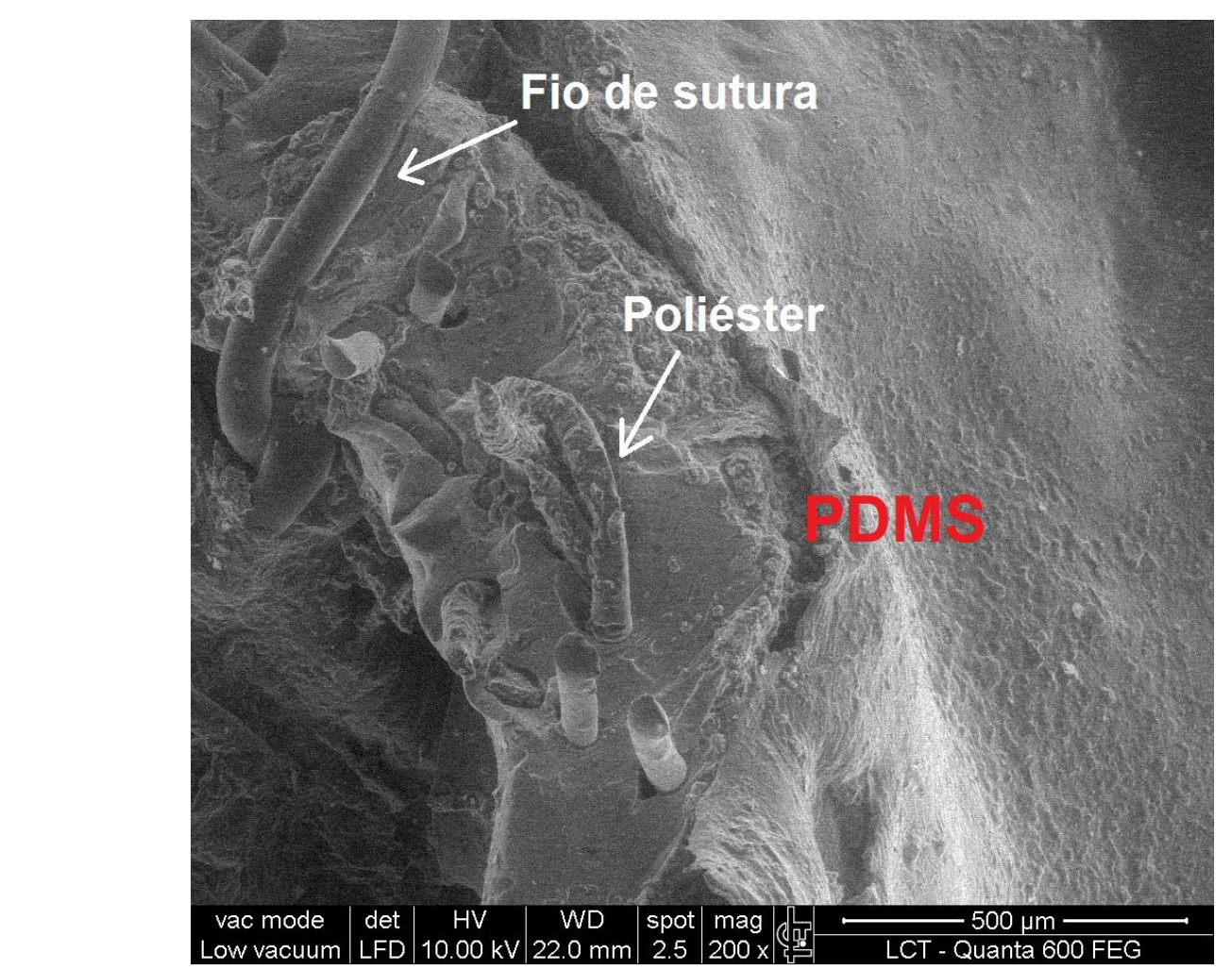

Figura 19 - Aproximação da imagem representada pela figura 18.

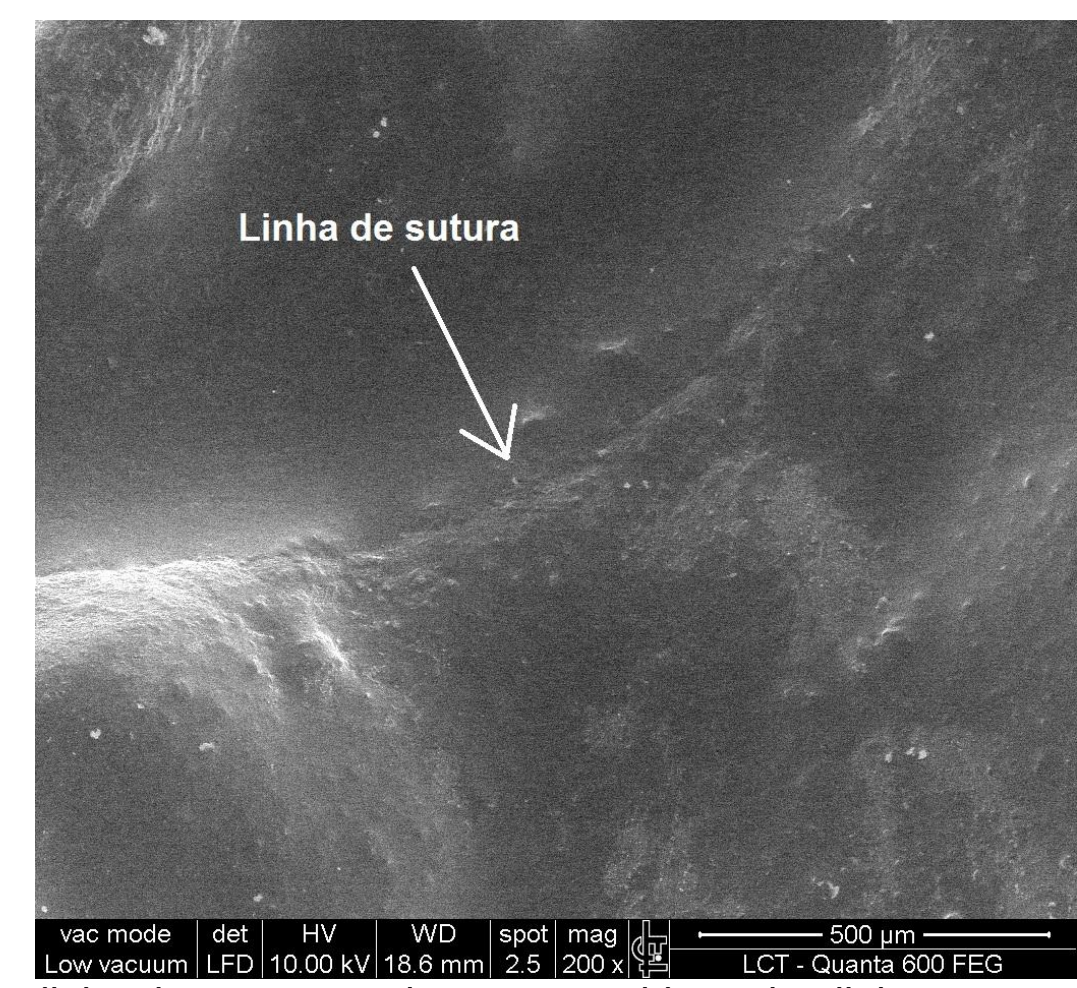

Figura 20 - linha de sutura recoberta por tecido endotelial. 


\section{Discussão}

Próteses vasculares são utilizadas há várias décadas para a restauração do fluxo sanguíneo em diversos territórios, mas apesar de terem funcionamento bem estabelecido para vasos de grande calibre, apresentam limitações para o uso em vasos de diâmetro inferior a $4 \mathrm{~mm}^{9}$.

A procura da prótese vascular ideal persegue a premissa de que a mesma tenha atributos semelhantes aos do vaso sanguíneo que pretende substituir. Entretanto, mesmo as próteses que são relativamente bem sucedidas têm apenas algumas características comuns aos vasos naturais, e outras que nunca foram alcançadas.

O desenvolvimento e o ensaio de nova prótese vascular pressupõe o implante deste novo dispositivo em modelo vivo para que as características do substituto sejam testadas em condições de fluxo sanguíneo pulsátil e das reações biológicas do organismo ao próprio material utilizado, tanto na superfície interna que fica em contato com o endotélio nativo, quanto na externa que sofre a reação tecidual inflamatória do hospedeiro sejam avaliadas.

No caso de estudo em vasos de pequeno calibre (de diâmetro igual ou inferior a $4 \mathrm{~mm}$ ) o modelo animal deve também se adequar às dimensões do implante. O modelo leporino tem sido utilizado como sistema para avaliação in vivo no ramo da engenharia vascular ${ }^{122}$ e o comportamento de coelhos no âmbito do aparelho circulatório é reconhecido como dos que mais se assemelha à fisiologia humana ${ }^{107,115,123}$. Por esses motivos foi o escolhido para 
este estudo, mas inerentes a essa decisão, vantagens e desvantagens ao método podem ser discutidas.

Dentre as vantagens estão a disponibilidade maior destes animais, no caso de nosso ambiente de pesquisa, fornecidos pelo biotério da própria instituição que mantém criatório próprio, e a facilidade de manutenção também em biotério em condições rotineiras de acompanhamento para a avaliação tardia do comportamento das próteses.

Essas vantagens se sobrepuseram em comparação com o modelo porcino, utilizado na fase piloto deste estudo. $O$ uso de porcos para a realização dos ensaios protéticos foi abandonado, apesar da grande resistência desses animais, devido à dificuldade da manutenção em biotério no perímetro urbano, ao crescimento exacerbado dos animais em curto período de tempo e ao comportamento das reações orgânicas no caso em questão caracterizada por hiperplasia intimal acentuada

Em relação às desvantagens do modelo leporino devem ser ressaltados a relativa fragilidade desses animais à manipulação cirúrgica, que se iniciam pela dificuldade da entubação orotraqueal, o que fez com este procedimento não fosse rotineiramente empregado, ao calibre dos vasos a serem manipulados, que levou ao uso da aorta infrarrenal para o ensaio em questão e a suscetibilidade à lesão neurológica caracterizada por paraplegia no pósoperatório.

A paraplegia nesse tipo de procedimento cirúrgico é decorrente de perfusão inadequada para a artéria espinhal ${ }^{124}$ e pode estar associada com oclusão do enxerto que equivale à trombose aguda da aorta, ao tempo de 
isquemia medular causada pelo clampeamento, ou à ligadura ou lesão de artérias lombares pela técnica operatória.

Em relação à aorta abdominal em coelhos, existem poucos estudos disponíveis. Um estudo feito com clampeamento de aorta mostrou que, após 21 minutos, a paraplegia foi de $90 \%$ e poderia ser prevenida com o uso de fármacos e, após 30 minutos, foi de $100 \%{ }^{125}$.

O tempo médio do clampeamento aórtico neste estudo foi de 52 minutos, porém não houve correlação significante do tempo de clampeamento com a paraplegia $(p=0,67)$. Isso pode estar relacionado ao fato de que esse tempo não significa o tempo total de oclusão continua da aorta, já que o fluxo sanguíneo foi liberado entre as anastomoses (condicionamento isquêmico).

Outro fator que poderia resultar em paraplegia seria oclusão imediata do enxerto e consequente trombose da aorta. Apesar da sabida relação da trombose da aorta com paraplegia, que corresponde a tempo de isquemia prolongado e definitivo, não foi possível estabelecer a relação entre oclusão do enxerto e a paraplegia, pois só foram realizados quatro cateterismos em coelhos paraplégicos. Em três desses demonstrou-se a oclusão e, em um demonstrou-se patência da prótese. A causa da paraplegia desse último animal pode ter sido a isquemia ou ligadura de artérias lombares.

Nos coelhos que apresentaram oclusão tardia do enxerto não foi observada paraplegia e os cateterismos desses animais demonstravam exuberante circulação colateral. Isso demonstra que houve uma oclusão gradual do enxerto, provavelmente com formação de hiperplasia intimal ou 
formação lenta de trombo em um tempo suficiente para que ocorresse reação do organismo e o estabelecimento da circulação.

A mortalidade perioperatória nos coelhos deste estudo foi de 35,94\% com tempo médio de sobrevida de dois dias e em apenas um animal foi realizada arteriografia, que apresentou oclusão da prótese. Essas mortes podem ter sido oriundas de erros técnicos transoperatórios ou por consequências hemodinâmicas (hemorragia), apesar de não ter sido feita autópsia nesses animais.

O PDMS foi o material escolhido para este estudo devido suas propriedades, como baixa trombogenicidade e toxicidade, qualidades essas essenciais para o uso médico ${ }^{100,101}$. O uso do poliéster como reforço ao silicone teve como objetivo prevenir rasgos durante a sutura da prótese, tendo em vista que o PDMS possui baixa tolerância ao rasgo. Esse revestimento demonstrouse útil, pois esses eventos não ocorreram durante a aplicação de nenhuma prótese. Consequentemente também não foram observados pseudoaneurismas.

A técnica de anastomose escolhida para implantação das próteses foi término-lateral. Embora o uso dessa técnica esteja relacionado ao alto fluxo turbulento e consequente aumento da hiperplasia intimal (devido à força de cisalhamento), esse fenômeno é mais descrito em implantes de veias do que em sintéticos, onde a força que o sangue exerce na parece da prótese tende a ser mais laminar e menos turbulenta ${ }^{128}$. Além disso, foi possível realizar o condicionamento isquêmico com aplicação de clamp no tubo durante a técnica 
término-lateral e assim maximizar a perfusão das artérias lombares e minimizar paraplegia no perioperatório.

Uma desvantagem citada em relação ao PDMS é sua hidrofobia. Um estudo com revestimento de gelatina-glutaraldeído apresentou resultados satisfatórios na diminuição da hidrofobia e consequente aumento da adesão de células endoteliais nesse material ${ }^{126}$. Esse revestimento serve como proposta para estudos futuros do PDMS como prótese vascular.

Considerando-se que o endotélio é responsável pela preservação do meio intravascular, é natural que seja grande a busca pela endotelização de enxertos, porém estudos apresentam resultados contraditórios no âmbito da porosidade das próteses. Teoricamente os poros são arcabouços para a passagem e habitação de células endoteliais para dentro do lúmen protético. Partiu-se então do pressuposto que quanto maior o espaço entre os nodos da prótese, maior seria a habitação $\operatorname{celular}^{40}$, porém esse conceito foi posto em dúvida com a teoria de que a porosidade ideal deveria ser intermediária, nem muito alta e nem muito baixa ${ }^{55}$. Dessa maneira uma porosidade intermediária evitaria a hiperplasia intimal, principal responsável pelas falhas nos implantes vasculares. O fato é que Lumsden et al (1996) ${ }^{58}$ apresentaram uma nova proposta de revestir tubos de PTFE com silicone não poroso afim de promover uma superfície lisa e uniforme para limitar o crescimento interno de tecido além da região transanastomótica. Os resultados foram satisfatórios. A hiperplasia intimal observada nesses tubos revestidos era menor em área e espessura. 
Baseado nesses resultados um modelo experimental foi desenvolvido para testar a hipótese de que o PDMS não poroso é uma prótese arterial adequada para vasos de pequeno calibre.

Para a avaliação das próteses em questão, foi protocolado que a patência seria comprovada sempre pela injeção de contraste na aorta (arteriografia feita por cateterismo retrogrado) e acompanhamento em longo prazo. Oclusões em menos de 30 dias são relacionadas a falhas cirúrgicas, como erro técnico na anastomose, posicionamento da prótese, dobras na prótese ou deficiência no escoamento ${ }^{70}$. Neste estudo realizamos avaliação da prótese em até 150 dias. Dentro desse limite de tempo procuramos realizar as arteriografias o mais tardiamente possível de acordo com a evolução clínica dos animais.

A taxa de patência da prótese de PDMS em 90 dias foi de $57 \%( \pm 11)$. Nordestgaard e colaboradores ${ }^{117}$ apresentaram trabalho semelhante, porém com próteses de PTFEe de $3 \mathrm{~mm}$ de diâmetro também implantadas em aorta de coelhos. Sua patência foi de 82\% em 90 dias. Em 2012 Zheng e colaboradores ${ }^{127}$ testaram prótese de policaprolactona revestida com argininaglicina-ácido aspártico em carótida de dez coelhos e a patência em quatro semanas foi de $100 \%$, porém os autores discutem o curto período de observação, sabido que um mês não é suficiente para ocorra regeneração vascular. Se considerarmos seguimento de apenas 30 dias teríamos então patência $87 \%( \pm 6,7)$.

As próteses que apresentaram oclusão não apresentaram nenhum grau de associação com tempo de clampeamento $(p=0,18)$. Sabendo que as principais causas de falhas nos implantes vasculares são hiperplasia intimal e 
formação de trombo ${ }^{69}$, acreditamos que, com exceção dos quadros agudos, essas foram as causas de oclusões nas próteses de PDMS.

O uso da arteriografia também possibilitou avaliar o grau de estenose das próteses que apresentaram fluxo patente. Mais de cinqüenta por cento dessas próteses não apresentaram nenhum grau de estenose. Aquelas que apresentaram qualquer grau de diminuição da luz protética puderam ser atribuídas ao crescimento da camada intimal, à formação de trombo ou falha na técnica de anastomose. Infelizmente não foi possível realizar em paralelo uma análise por microscopia óptica para comprovar esses eventos, pois o material de PDMS não permitiu corte ao micrótomo. De uma maneira amostral foi então realizada microscopia eletrônica a fim de verificar possível endotelização das próteses. As peças encaminhadas apresentaram imagem compatível com crescimento endotelial a partir da anastomose.

Sabendo que o PDMS possui qualidades que o tornam um excelente material para próteses, principalmente por ser pouco trombogênico, este estudo desmistificou seu uso como substituto arterial e pode ser considerado o primeiro passo para novas pesquisas nessa área. Testes físicos com o material, como por exemplo teste de força tensil, o qual utiliza equipamento específico para medição da resistência do material frente a uma determinada tensão, poderá acrescentar informações importantes para aplicação clínica desse material. Além disso, análises comparativas entre tubos não porosos e com baixa porosidade, estudos com diferentes diâmetros internos de prótese e estudos comparativos entre diferentes técnicas de anastomose poderão contribuir para o futuro do PDMS no ramo da cirurgia vascular. 
Naturalmente, o custo das eventuais próteses de PDMS deverá ser um componente importante na sua utilização como material alternativo de substituição vascular. Estudos futuros deverão esclarecer essa importante questão. 


\section{Conclusão}

- Foi possível concluir com este estudo que o PDMS demonstrou-se um material adequado como prótese vascular e para futuras pesquisas nesse ramo.

- O uso da fluoroscopia na avaliação das próteses foi de fundamental importância na determinação da patência dos implantes.

- O material de PDMS apresentou facilidades de implantação cirúrgica e boa tolerância ao rasco promovido pelo reforço de poliéster

- A prótese de PDMS apresentou facilidade de remoção no pós-operatório e ausência de pseudoaneurismas.

- Apesar da alta taxa de mortalidade, o coelho pode ser considerado um bom modelo experimental para estudos de implantação de próteses vasculares. 


\section{Referências}

1. Moore WS. Vascular and endovascular surgery: a comprehensive review expert consult. 8th ed. Philadelphia: Elsevier Saunders; 2013.

2. Sarkar S, Salacinski HJ, Hamilton G, Seifalian AM. The mechanical properties of infrainguinal vascular bypass grafts: their role in influencing patency. Eur J Vasc Endovasc Surg. 2006;31(6):627-36.

3. Moll FL, Powell JT, Fraedrich G, Verzini F, Haulon S, Waltham M, van Herwaarden JA, Holt PJE, van Keulen JW, Rantner B, Schlösser FJV, Setacci F, Ricco J-B. Management of abdominal aortic aneurysms clinical practice guidelines of the european society for vascular surgery. Eur $J$ Vasc Endovasc. 2011;41(1):S1-S58.

4. Stollwerck PL, Kozlowski B, Sandmann W, Grabitz K, Pfeiffer T. Long-term dilatation of polyester and expanded polytetrafluoroethylene tube grafts after open repair of infrarenal abdominal aortic aneurysms. J Vasc Surg. 2011;53(6):1506-13.

5. Yamamoto H, Yamamoto F, Ishibashi K, Liu K-X, Yamaura G, Chida Y, Motokawa M, Tanaka F. Long-term outcomes of open surgical repair for ruptured iliac artery aneurysms. Ann Vasc Surg. 2011;25(6):740-7.

6. Johnson WC, Lee KK. A comparative evaluation of polytetrafluoroethylene, umbilical vein, and saphenous vein bypass grafts for femoral-popliteal above-knee revascularization: a prospective randomized department of veterans affairs cooperative study. $J$ Vasc Surg. 2000;32(2):268-77.

7. Curi MA, Skelly CL, Meyerson SL, Woo DH, Desai TR, McKinsey JF, Bassiouny HS, Katz D, Gewertz BL, Schwartz LB. Conduit choice for above-knee femoropopliteal bypass grafting in patients with limbthreatening ischemia. Ann Vasc Surg. 2002;16(1):95-101.

8. Solaković E, Totić D, Solaković S. Femoro-popliteal bypass above knee with saphenous vein vs synthetic graft. Bosn J Basic Med Sci. 2008;8(4):367-72.

9. Cavallaro A, Sterpetti AV, Dimarzo L, Sapienza P. Worsening of Preoperative Foot Ischemia After Occlusion of Polytetrafluoroethylene Femorotibial Grafts: A Comparison With Saphenous Vein Grafts. Ann Vasc Surg. In press 2013.

10. Loh SA, Howell BS, Rockman CB, Cayne NS, Adelman MA, Gulkarov I, Veith FJ, Maldonado TS. Mid- and long-term results of the treatment of 
infrainguinal arterial occlusive disease with precuffed expanded polytetrafluoroethylene grafts compared with vein grafts. Ann Vasc Surg. 2013;27(2):208-17.

11. Davies MG, Dale H, Austarheim AM, Gulbrandsen TF, Svendsen E, Hagen PO. Suppression of intimal hyperplasia in experimental vein grafts by oral L-arginine supplementation and single ex vivo immersion in deferoxamine manganese. J Vasc Surg. 1996;23(3):410-20.

12. Abbott WM; Green RM; Matsumoto T, Wheeler JR, Miller N, Veith FJ, Suggs WD, Hollier L, Money S, Garrett HE. Prosthetic above-knee femoropopliteal bypass grafting: results of a multicenter randomized prospective trial. J Vasc Surg. 1997;25(1):19-28.

13. Ku DN, Allen RC. Vascular Grafts. In: Bronzino JD. The biomedical engineering handbook. 2nd ed. Boca Raton: CRC Press LLC; 2000. p.128-1-7. 2v.

14. Fulton GJ, Davies MG, Barber L, Gray JL, Svendsen E, Hagen PO. Local effects of nitric oxide supplementation and suppression in the development of intimal hyperplasia in experimental vein grafts. Eur $J$ Vasc Endovasc. 1998;15(4):279-89.

15. Martin RS 3rd, Edwards WH, Mulherin JL Jr, Edwards WH Jr, Jenkins JM, Hoff SJ. Cryopreserved saphenous vein allografts for below-knee lower extremity revascularization. Ann Surg. 1994;219(6):664-70.

16. Barshes NR, Ozaki CK, Kougias P, Belkin M. A cost-effectiveness analysis of infrainguinal bypass in the absence of great saphenous vein conduit. $J$ Vasc Surg. In press 2013.

17. Alcántara EM, Marshall LM, Rodrigues VV, Rosado CF. Mechanics of biomaterials: vascular graft prosthesis. Appli Engin Mech Med. 2005;5:A125.

18. Cleary MA, Geiger E, Grady C, Best C, Naito Y, Breuer C. Vascular tissue engineering: the next generation. Trends in Molecular Medicine. 2012;18(7):394-404.

19. Conte MS. The ideal small arterial substitute: a search for the Holy Grail? FASEB J. 1998;12(1):43-5.

20. Kakisis JD, Liapis CD, Breuer C, Sumpio BE. Artificial blood vessel: the Holy Grail of peripheral vascular surgery. J Vasc Surg. 2005;41(2):349-54. 
21. Voorhees Jr AB, Jaretzki III A, Blakemore $A H$. The use of tubes constructed from vinyon " $n$ " cloth in bridging arterial defects - a preliminary report. Ann Surg. 1952;135(3):332-6.

22. Edwards WS, Tapp JS. Chemically treated nylon tubes as arterial grafts. Surgery. 1955;38(1):61-70.

23. Harrison JH, Lincoln AF, Swanson DS. A comparison of the tissue reactions to plastic materials: dacron, ivalon sponge, nylon, orlon, and teflon. AMA Arch Surg. 1957;74(1):139-44.

24. United States Patent. Janet Moreland. Vascular graft. US 5413598, 15 Jul. 1994, 9 Mai, 1995.

25. Ratner BD, Hoffman AS, Schoen FJ, Lemons JE. Biomaterial science: an introduction to materials in medicine. 3th ed. Waltham: Academic Press; 2012.

26. Sheehan SJ, Rajah SM, Kester RC. Effect of preclotting on the porosity and thrombogenicity of knitted Dacron grafts. Biomaterials. 1989;10(2):759.

27. Kang SS, Petsikas D, Murchan P, Cziperle DJ, Ren D, Kim DU, Greisler HP. Effects of albumin coating of knitted Dacron grafts on transinterstitial blood loss and tissue ingrowth and incorporation. Cardiovasc Surg. 1997;5(2):184-9.

28. United States Patent. Indu Kapadia, Ibrahim M. Ibrahim. Woven Vascular graft. US 4816028, 1 Jul 1987, 28 Mar 1989.

29. United States Patent. Peter J. Schmitt. Self-Supporting Woven Vascular graft. US 5282848, 19 Abr 1993, 1 Fev 1994.

30. Edwards WS. Progress in synthetic graft development: an improved crimped graft of teflon. Surgery. 1959;45(2):298-309.

31. Soyer $T$, Lempinen $M$, Cooper $P$, Norton L, Eiseman B. A new venous prosthesis. Surgery. 1972;72(6):864-72.

32. Matsumoto $\mathrm{H}$, Hasegawa $T$, Fuse $\mathrm{K}$, Yamamoto M, Saigusa M. A new vascular prosthesis for a small caliber artery. Surgery. 1973;74(4):519-23.

33. Mima A. Hemodialysis vascular access dysfunction: molecular mechanisms and treatment. Ther Apher Dial. 2012;16(4):321-7.

34. Sabanegh ES Jr, Downey JR, Sago AL. Long-segment ureteral replacement with expanded polytetrafluoroethylene grafts. Urology. 1996;48(2):312-6. 
35. Marin ML, Veith FJ, Lyon RT, Cynamon J, Sanchez LA. Transfemoral endovascular repair of iliac artery aneurysms. $A m \mathrm{~J}$ Surg. 1995;170(2):179-82.

36. Moore WS, Ahn SS. Endovascular surgery. 4th ed. Philadelphia: Saunders Elsevier; 2011.

37. Alsac JM, Julia P, Fabiani JN. Antegrade, covered, self-expanding stent as an iliac extension in a bifurcated endograft: a feasible technical maneuver for challenging aortoiliac aneurysmal anatomy. Ann Vasc Surg. 2011 Aug;25(6):842-5.

38. Rancic Z, Pecoraro F, Pfammatter T, Mayer D, Veith FJ, Lachat M. Less Invasive (Common) Femoral Artery Aneurysm Repair Using Endografts and Limited Dissection. Eur J Vasc Endovasc Surg. In Press 2013.

39. Verzini F, De Rango P, Isernia G, Simonte G, Farchioni L, Cao P. Results of the "endovascular treatment first" policy for infrapopliteal disease. $J$ Cardiovasc Surg. 2012;53(Suppl 1):179-88. NÃO TENHO ESSE

40. Berger K, Sauvage L, Rao A, Wood S. Healing of arterial prostheses in man: its incompleteness. Ann Surg. 1972;175(1):118-27.

41. Mondaga S, Higgs A. The vascular endothelium I. Heidelberg: Springer; 2010.

42. Dusse LMS, Vieira LM, Carvalho MG. Revisão sobre óxido nítrico. J Bras Patol Med Lab. 2003;39(4):343-50.

43. Cowan CL, Cohen RA. Two mechanisms mediate relaxation by bradykinin of pig coronary artery: NO-dependent and independent responses. $\mathrm{Am} \mathrm{J}$ Physiol. 1991;261(3):H830-5.

44. Bahia L, Aguiar LGK, Villela NR, Bottino D, Bouskela E. Endotélio e aterosclerose. Rev SOCERJ. 2004:17(1);26-32.

45. Raffetto JD, Yu P, Reslan OM, Xia Y, Khalil RA. Endothelium-dependent nitric oxide and hyperpolarization-mediated venous relaxation pathways in rat inferior vena cava. J Vasc Surg. 2012;55(6):1716-25.

46. Rubanyi GM, Polokoff MA. Endothelins: molecular biology, biochemistry, pharmacology, physiology, and pathophysiology. Pharmacol. 1994:46(3);328-415.

47. Goodfriend TL, Elliott ME, Catt KJ. Angiotensin receptors and their antagonists. Drug Therapy. 1996:334(25);1649-54. 
48. Carvalho MHC, Nigro D, Lemos VS, Tostes RCA, Fortes ZB. Hipertensão arterial: o endotélio e suas múltiplas funções. Rev Bras Hipertens. $2001 ; 8(1): 76-88$.

49. Crombez M, Chevallier P, Gaudreault RC, Petitclerc E, Mantovani D, Laroche G. Improving arterial prosthesis neo-endothelialization: application of a proactive VEGF construct onto PTFE surfaces. Biomaterials. 2005;26(35):7402-9.

50. Clowes AW, Zacharias RK, Kirkman TR. Early endothelial coverage of synthetic arterial grafts: porosity revisited. Am J Surg. 1987;153(5):501-4.

51. Bengtsson L, Radegran K, Haegerstrand A. A new and simple technique to achieve a confluent and flow resistant endothelium on vascular ePTFEgrafts using human serum. Eur J Vasc Surg. 1994;8(2):182-87.

52. Mellander S, Fogelstrand $\mathrm{P}$, Enocson $\mathrm{K}$, Johansson BR, Mattsson $\mathrm{E}$. Healing of PTFE grafts in a pig model recruit neointimal cells from different sources and do not endothelialize. Eur J Vasc Endovasc. 2005;30(1):6370.

53. Komori K, Yamamura S, Ishida M, Matsumoto T, Kuma S, Eguchi D, Yonemitsu Y, Onohara T, Sugimachi K. Acceleration of Impairment of endothelium-dependent responses under poor runoff conditions in canine autogenous vein grafts. Eur J Vasc Endovasc Surg. 1997;14(6):475-81.

54. Zilla $P$, Bezuidenhout $D$, Human $P$. Prosthetic vascular grafts: Wrong models, wrong questions and no healing. Biomaterials. 2007;28(34):500927.

55. Golden MA, Hanson SR, Kirkman TR, Schneider PA, Clowes AW. Healing of polytetrafluorethylene arterial grafts is influenced by graft porosity. $J$ Vasc Surg. 1990;11(6):838-45.

56. Reidy MA, Chao SS, Kirkman TR, Clowes AW. Endothelial regeneration. VI. Chronic nondenuding injury in baboon vascular grafts. Am J Pathol. $1986 ; 123(3): 432-9$.

57. Clowes AW., Kirkman TR, Reidy MA. Mechanisms of arterial graft healing. Rapid transmural capillary ingrowth provides a source of intimal endothelium and smooth muscle in porous PTFE prostheses. Am J Pathol. 1986;123(2):220-230.

58. Lumsden AB, Chen C, Coyle KA, Ofenloch JC, Wang J, Yasuda HK, Hanson SR. Nonporous silicone polymer coating of expanded polytetrafluoroethylene grafts reduces graft neointimal hyperplasia in dog and baboon models. J Vasc Surg. 1996;24(5):825-33. 
59. Contreras MA, Quist WC, Logerfo FW. Effect of porosity on small-diameter vascular graft healing. Microsurgery. 2000;20(1):15-21.

60. Herring M, Gardner A, Glover J. A single-staged technique for seeding vascular grafts with autogenous endothelium. Surgery. 1978;84(4):498504.

61. Zilla P, Deutsch M, Meinhart J, Puschmann R, Eberl T, Minar E, Dudczak $R$, Lugmaier $H$, Schmidt $P$, Noszian I, Fischlein $T$. Clinical in vitro endothelialization of femoropopliteal bypass grafts: An actuarial follow-up over three years. J Vasc Surg. 1994;19(3):540-8.

62. Haegerstrand A, Gillis C, Bengtsson L. Serial cultivation of adult human endothelium from the great saphenous vein. J Vasc Surg. 1992;16(2):2805.

63. Hsu SH, Tsai IJ, Lin DJ, Chen DC. The effect of dynamic culture conditions on endothelial cell seeding and retention on small diameter polyurethane vascular grafts. Med Eng Phys. 2005;27(3):267-72.

64. Kern PA, Knedler A, Eckel RH. Isolation and culture of microvascular endothelium from human adipose tissue. J Clin Invest. 1983;71(6):1822-9.

65. Hinds MT, Ma M, Tran N, Ensley AE, Kladakis SM, Vartanian KB, Markway BD, Nerem RM, Hanson SR. Potential of baboon endothelial progenitor cells for tissue engineered vascular grafts. J Biomed Mater Res A. 2008;86(3):804-12.

66. Graham LM, Burkel WE, Ford JW, Vinter DW, Kahn RH, Stanley JC. Expanded polytetrafluoroethylene vascular prostheses seeded with enzymatically derived and cultured canine endothelial cells. Surgery. 1982;91(5):550-9.

67. Koveker G, Burkel W, Graham L, Wakefield T, Stanley J. Endothelial cell seeding of expanded polytetrafluoroethylene vena cava conduits: effects on luminal production of prostacyclin, platelet adherence, and fibrinogen accumulation. J Vasc Surg. 1988;7(4):600-5.

68. Ombrellaro MP, Stevens SL, Kerstetter K, Freeman MB, Goldman MH. Healing characteristics of intraarterial stented grafts: effect of intraluminal position on prosthetic graft healing. Surgery. 1996;120(1):60-70.

69. Li FD, Sexton KW., Hocking KM, Osgood MJ, Eagle S, Cheung-Flynn J, Brophy CM, Komalavilas P. Intimal thickness associated with endothelial dysfunction in human vein grafts. J Surg Res. 2013;180(1):e55-62.

70. Davies MG, Hagen PO. Pathophysiology of vein graft failure: a review. Eur J Vasc Endovasc Surg. 1995;9(1):7-18. 
71. Bhattacharya V, McSweeney PA, Shi Q, Bruno B, Ishida A, Nash R, Storb RF, Sauvage LR, Hammond WP, Wu MH. Enhanced endothelialization and microvessel formation in polyester grafts seeded with CD34(+) bone marrow cells. Blood. 2000;95(2):581-5.

72. Rotmans JI, Heyligers JM, Verhagen HJ, Velema E, Nagtegaal MM, de Kleijn DP, de Groot FG, Stroes ES, Pasterkamp G. In vivo cell seeding with anti-CD34 antibodies successfully accelerates endothelialization but stimulates intimal hyperplasia in porcine arteriovenous expanded polytetrafluoroethylene grafts. Circulation. 2005;112(1):12-8.

73. Conte MS, Choudhury RP, Shirakowa M, Fallon JT, Birinyi LK, Choudhry RP. Endothelial cell seeding fails to attenuate intimal thickening in ballooninjured rabbit arteries. J Vasc Surg. 1995;21(3):413-21.

74. Jobst BJ, Riegger GA, Griese DP. Endothelial cell seeding fails to prevent intimal hyperplasia following arterial injury in the rat carotid model. Cardiovasc Drugs Ther. 2009;23(5):343-53.

75. Zelenock GB, Huber TS, Messina LM, Lumsden AB, Moneta GL. Mastery of vascular and endovascular surgery. Philadelphia: Lippincott Williams \& Wilkins; 2006.

76. Bronzino J. The biomedical engineering handbook. 2nd ed. Boca Raton: CRC Press; 2000. 2v.

77. Meyerson SL, Skelly CL, Curi MA, Shakur UM, Vosicky JE, Glagov S, and Schwartz LB. The effects of extremely low shear stress on cellular proliferation and neointimal thickening in the failing bypass graft. $J$ Vasc Surg. 2001;34(1):90-7.

78. Paszkowiak JJ, Dardik A. Arterial wall shear stress: observations from the bench to the bedside. Vasc Endovascular Surg. 2003;37(1):47-57.

79. Papaioannou TG, Stefanadis C. Vascular wall shear stress: basic principles and methods. Hellenic J Cardiol. 2005;46(1):9-15.

80. Kohler TR, Kirkman TR, Kraiss LW, Zierler BK, Clowes AW. Increased blood flow inhibits neointimal hyperplasia in endothelialized vascular grafts. Circ Res. 1991;69(6):1557-65.

81. Kraiss LW, Kirkman TR, Kohler TR, Zierler B, Clowes AW. Shear stress regulates smooth muscle proliferation and neointimal thickening in porous polytetrafluoroethylene grafts. Arterioscler Thromb. 1991;11(6):1844-52.

82. Kraiss LW, Geary RL, Mattsson EJ, Vergel S, Au YP, Clowes AW. Acute reductions in blood flow and shear stress induce platelet-derived growth 
factor-A expression in baboon prosthetic grafts. Circ Res. 1996;79(1):4553.

83. Williams DF. Definitions in biomaterials: proceedings of a consensus conference of the European Society for Biomaterials. Chester: Elsevier; 1987.

84. Teebken OE, Haverich A. Tissue engineering of small diameter vascular grafts. Eur J Vasc Endovasc. 2002;23(6):475-85.

85. Almeida, AT. Obtenção de superfícies hemocompatíveis por meio da modificação de materiais poliméricos pela radiação ionizante. São Paulo: Universidade de São Paulo; 2000.

86. Drobny JG. Handbook of thermoplastic Elastomers. Norwich: Plastics Design Library; 2007. p.215-234.

87. Lening KL, Corradini P, Cross LK, Fox RB, Korshak VV, Plate NA, Ring V, Smets G, Sur K, Tsuruta T. Main definitions of terms relating to polymers 1974. Polymer Science U.S.S.R. 1978;20(5):1316-28.

88. McKeen LW. The effect of temperature and other factors on plastics and elastomers. 2nd ed. Norwich: Plastics Design Library; 2008. p.1-39.

89. Asakura T, Demura M. Oriented fibers and polymers. In: Ando I, Asakura T. Solid State NMR of Polymers. Tokyo: Elsevier; 1998. v.84, p.307-326. (Studies in Physical and Theoretical Chemistry).

90. Lucas EF, Soares BG, Monteiro EEC. Caracterização de polímeros: determinação de peso molecular e análise térmica. Rio de Janeiro: epapers; 2001.

91. Young RJ, Lovell PA. Introduction to polymers. 3th ed. Boca Raton: CRC Press, 2011. p.3-14.

92. Kipping FS, Lloyd LL. Organic derivative of silicone: triphenylsilicol and alkyloxysilicon chlorides. Proc Chem Soc. 1904;20(15):449-59.

93. Garcia MHF, Farias SB, Ferreira BG. Determinação quantitativa da concentração de silicone em antiespumantes por espectroscopia FT-IR / ATR e calibração multivariada. Polímeros. 2004;14(5):322-5.

94. Kuo ACM. Poly (dimethylsiloxane). In: Mark JE. Polymer data handbook. Oxford: Oxford University Press; 1999. p.411-35.

95. Sanislow CA Jr, Zuidema GD. The use of slicone t-tubes in reconstructive biliary surgery in dogs. J Surg Res. 1963;3:497-502. 
96. Leininger RI, Mirkovitch V, Peters A, Hawks WA. Change in properties of plastics during implantation. Trans Am Soc Artif Intern Organs. 1964;10:320-2.

97. Gladilin E, Gabrielova B, Montemurro P, Hedén P. Customized planning of augmentation mammaplasty with silicon implants using three-dimensional optical body scans and biomechanical modeling of soft tissue outcome. Aesthetic Plast Surg. 2011;35(4):494-501.

98. Oliver DW, Walker M. Walters A, Chatrath P, Lamberty BGH. Anti-silicone antibodies and silicone containing breast implants. British Journal of Plastic Surgery. 2000;53(5);410-4.

99. Montague DK. Penile prosthesis implantation in the era of medical treatment for erectile dysfunction. Urol Clin N Am. 2011;38(2):217-25.

100. Spiller D, Losi P, Briganti E, Sbrana S, Kull S, Martinelli I, Soldani G. PDMS content affects in vitro hemocompatibility of synthetic vascular grafts. J Mater Sci Mater Med. 2007;18(6):1097-104.

101. Simmons A, Padsalgikar AD, Ferris LM, Poole-Warren LA. Biostability and biological performance of a PDMS-based polyurethane for controlled drug release. Biomaterials. 2008;29(20):2987-95.

102. Egdahl $\mathrm{RH}$. Silicone rubber as aortic grafting material. AMA Arch Surg. 1955;71(5):694-696.

103. Bass A, Krupski WC, Hanson SR, Dodson T, Lumsden A, White D, Harker LA, Kelly AB. Exteriorized chronic aorto-caval arteriovenous access shunts in the baboon (Papio cynocephalus). J Med Primatol. 1993;22(6):331-9.

104. Okoshi T, Soldani G, Goddard M, Galletti PM. Very small-diameter polyurethane vascular prostheses with rapid endothelialization for coronary artery bypass grafting. $J$ Thorac Cardiovasc Surg. 1993;105(5):791-5.

105. Drasler WJ, Wilson GJ, Stenoien MD, Jenson ML, George SA, Dutcher RG, Possis ZC. A spun elastomeric graft for dialysis access. ASAIO J. 1993;39(2):114-9.

106. Larena-Avellaneda A, Dittmann G, Haacke C, Graunke F, Siegel R, Dietz UA, Debus ES. Silicone-based vascular prosthesis: assessment of the mechanical properties. Ann Vasc Surg. 2008;22(1):106-14.

107. Byrom MJ, Bannon PG, White GH, Martin KC. Animal models for the assessment of novel vascular conduits. J Vasc Surg. 2010;52(1):176-95. 
108. Raymundo, MM, Goldim JR. Ética da pesquisa em modelos animais. Bioética. 2002;10(1):31-44.

109. Aufderheide AC. The scientific study of mummies. Cambridge: Cambridge University Press; 2003.

110. Rashid ST, Salacinski HJ, Hamilton G, Seifalian AM. The use of animal models in developing the discipline of cardiovascular tissue engineering: a review. Biomaterials. 2004;25(9):1627-37.

111. da Costa RFB, Fagundes DJ. Modelos experimentais de hiperplasia intimal: efeitos da radiação ionizante. Acta Cir. Bras. 2002;17(3):189-93.

112. Narayanaswamy $M$, Wright KC, Kandarpa K. Animal models for atherosclerosis, restenosis, and endovascular graft research. J Vasc Interv Radiol. 2000;11(1):5-17.

113. Wolfensohn S, Lloyd M. Handbook of laboratory animal management and welfare. 2nd ed. Oxford: Blackwell Science; 1998.

114. Abbott WM, Callow A, Moore W, Rutheford R, Veith F, Weinberg S. Evaluation and performance standards for arterial prostheses. J Vasc Surg. 1993:17(4):746-56.

115. Lidman DH, Faibisoff B, Daniel RK. Expanded polytetrafluoroethylene as a microvascular graft: an experimental study. J Microsurg. 1980;1(6):447-56.

116. Lopez-Soler RI, Brennan MP, Goyal A, Wang Y, Fong P, Tellides G, Sinusas A, Dardik A, Breuer C. Development of a mouse model for evaluation of small diameter vascular grafts original. J Surg Res. 2007,139(1):1-6.

117. Nordestgaard AG, Buckels JAC, Wilson SE. Platelet antagonists eliminate thromboembolic complications of small-diameter polytetrafluoroethylene arterial prostheses. J Vasc Surg. 1987;5(1):110-117.

118. Instituto Nacional de Propridade Industrial. Nelson De Luccia, Thiago Paes de Barros De Luccia. Prótese vascular feita em silicone. BR n. PI 0704867-0, 18 Jun. 2007, 10 Fev. 2009.

119. Harcort-Brown F. Textbook of rabbit medicine. Philadelphia: ButterworthHeinemann; 2002. p.121-39.

120. Rodríguez, G. (2007). Lecture notes on generalized linear models. Disponível em: http://data.princeton.edu/wws509/notes/.

121. Botelho F, Silva C, Cruz F. Epidemiologia explicada: análise de sobrevivência. Acta Urologica. 2009;26(4):33-8. 
122. Wong $A H$, Waugh JM, Amabile PG, Yuksel E, Dake MD. In vivo vascular engineering: directed migration of smooth muscle cells to limit neointima. Tissue Eng. 2002;8(2):189-99.

123. van der Lei $\mathrm{B}$, Robinson $\mathrm{PH}$, Bartels $\mathrm{HL}$, Wildevuur CR. Microarterial grafting into the carotid artery of the rabbit: some considerations concerning species-dependent thrombogenicity. $\mathrm{Br} J$ Plast Surg. 1989;42(1):59-64.

124. Matsuyama K, Chiba Y, Ihaya A, Kimura T, Tanigawa N, Muraoka R. Effect of spinal cord preconditioning on paraplegia during cross-clamping of the thoracic aorta. Ann Thorac Surg. 1997;63(5):1315-20.

125. Wisselink W, Money SR, Crockett DE, Nguyen JH, Becker MO, Farr $\mathrm{GH}$, Hollier $\mathrm{LH}$. Ischemia-reperfusion injury of the spinal cord: protective effect of the hydroxyl radical scavenger dimethylthiourea. $J$ Vasc Surg. 1994;20(3):444-91.

126. Ai H, Mills DK, Jonathan AS, Jones SA. Gelatin-glutaraldehyde crosslinking on silicone rubber to increase endothelial cell adhesion and growth. In Vitro Cell Dev Biol Anim. 2002;38(9):487-92.

127. Zheng W, Wang Z, Song L, Zhao Q, Zhang J, Li D, Wang S, Han J, Zheng $X L$, Yang Z, Kong D. Endothelialization and patency of RGDfunctionalized vascular grafts in a rabbit carotid artery model. Biomaterials. 2012;33(10):2880-91.

128. Loh SA, Howell BS, Rockman CB, Cayne NS, Adelman MA, Gulkarov I, Veith FJ, Maldonado TS. Mid- and long-term results of the treatment of infrainguinal arterial occlusive disease with precuffed expanded polytetrafluoroethylene grafts compared with vein grafts. Ann Vasc Surg. 2013;27(2):208-17. 